Prepared in cooperation with the U.S. Army Corps of Engineers and U.S. Fish and Wildlife Service

\title{
Visual Basic, Excel-Based Fish Population Modeling Tool- The Pallid Sturgeon Example
}

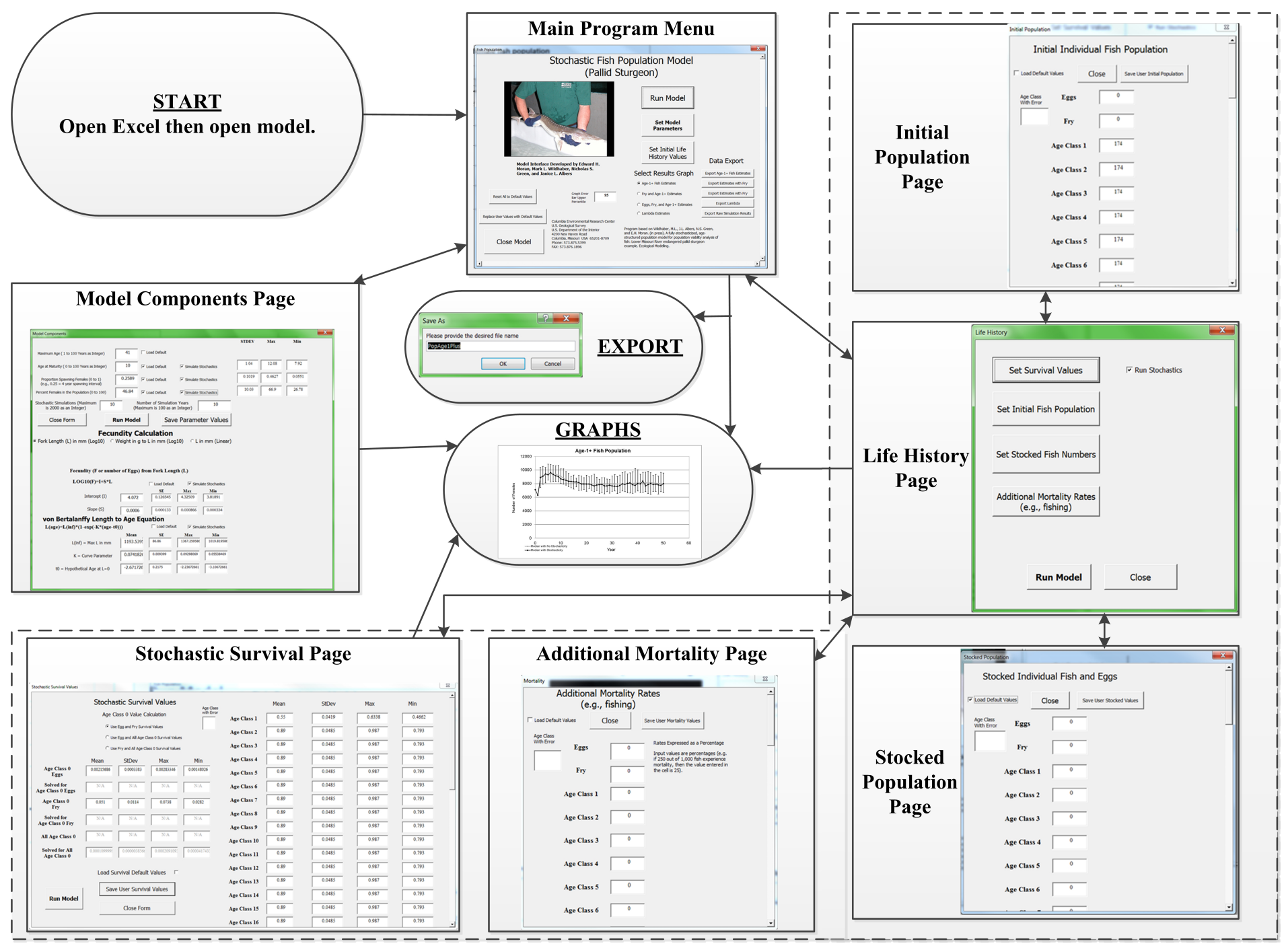

Open-File Report 2016-1009 
Cover. Figure 1 of this report. 


\section{Visual Basic, Excel-Based Fish Population Modeling Tool-The Pallid Sturgeon Example}

By Edward H. Moran, Mark L. Wildhaber, Nicholas S. Green, and Janice L. Albers

Prepared in cooperation with the U.S. Army Corps of Engineers and U.S. Fish and Wildlife Service

Open-File Report 2016-1009 


\title{
U.S. Department of the Interior SALLY JEWELL, Secretary
}

\section{U.S. Geological Survey Suzette M. Kimball, Director}

\author{
U.S. Geological Survey, Reston, Virginia: 2016
}

For more information on the USGS - the Federal source for science about the Earth, its natural and living resources, natural hazards, and the environment—visit http://www.usgs.gov or call 1-888-ASK-USGS.

For an overview of USGS information products, including maps, imagery, and publications, visit http://www.usgs.gov/pubprod/.

Any use of trade, firm, or product names is for descriptive purposes only and does not imply endorsement by the U.S. Government.

Although this information product, for the most part, is in the public domain, it also may contain copyrighted materials as noted in the text. Permission to reproduce copyrighted items must be secured from the copyright owner.

Suggested citation:

Moran, E.H., Wildhaber, M.L., Green, N.S., and Albers, J.L., 2016, Visual basic, Excel-based fish population modeling tool—The pallid sturgeon example: U.S. Geological Survey Open-File Report 2016-1009, 20 p., http://dx.doi. org/10.3133/ofr20161009.

ISSN 0196-1497 (print)

ISSN 2331-1258 (online)

ISBN 978-1-4113-4002-2 


\section{Preface}

This report documents a spreadsheet-based model for forecasting fish populations that was developed in Microsoft Excelß 2010 in concert with Microsoft Visual Basic for Applications (http://dx.doi.org/10.5066/F7057D0Z) using pallid sturgeon (Scaphirhynchus albus) as an example (see Wildhaber and others, 2015). The spreadsheet-based model has been tested for accuracy by comparing modeling results to those published by Wildhaber and others (2015). If users find or suspect errors, please contact the U.S. Geological Survey (USGS).

Extensive testing has been done by the authors and reviewers to ensure the Excel-based model is error free. Even so, errors possibly exist in the Excel-based model. The distribution of the spreadsheet model does not constitute any warranty by the USGS, and no responsibility is assumed by the USGS in connection therewith. 


\section{Acknowledgments}

The report was prepared in cooperation with the U.S. Army Corps of Engineers and U.S. Fish and Wildlife Service under the U.S. Geological Survey Science Support Program and Interagency Agreement. We would also like to thank R. Scott and A. Davis for help in development of the Excel/Visual Basic interface. 


\section{Contents}

Abstract
Introduction
Modeling Tool Example
Modeling Considerations
Model Usage
$\quad$ Setting Model Parameters
$\quad$ Setting Initial Life History Values
$\quad$ Setting Stocking Values
$\quad$ Outputs
Closing and Saving

\section{Figures}

1. Screenshot showing flow chart of linkages between model inputs and outputs ............3

2. Screenshot showing initial screen on model opening .....................................................

3. Screenshot showing "Fish Population" window (main model page) ..................................5

4. Screenshot showing "Model Components" window ........................................................6

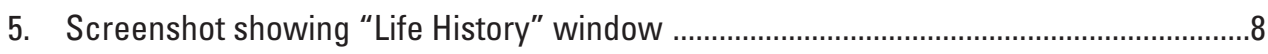

6. Screenshot showing "Stochastic Survival Values" window ..............................................

7. Screenshot showing "Initial Population" window ............................................................11

8. Screenshot showing "Stocked Population" window .....................................................12

9. Screenshot showing "Mortality" window .....................................................................13

10. Screenshot showing status bar reporting model progress ...........................................13

11. Screenshot showing notification that the simulations have completed and how long they took to run .............................................................................................

12. Screenshot showing final notification that the simulations have completed.................14

13. Graph showing age-1+ female population numbers ......................................................14

14. Graph showing fry and age-1+ female population numbers combined ........................15

15. Graph showing egg, fry, and age-1+ female population numbers combined .................16

16. Graph showing annual median lambda with extinctions .............................................16

17. Screenshot showing "Save As" window .......................................................................

18. Screenshot showing "Results Exported!" completion notice window ..........................17

19. Screenshot showing deterministic spreadsheet data saved .........................................17

20. Screenshot showing stochastic spreadsheet data saved ..............................................18

21. Graph showing age-1+ population saved figure ..........................................................18 


\section{Conversion Factors}

SI to Inch/Pound

\begin{tabular}{lcc}
\hline Multiply & By & To obtain \\
\hline & Length & \\
\hline millimeter $(\mathrm{mm})$ & 0.03937 & inch (in.) \\
\hline gram $(\mathrm{g})$ & Weight & \\
\hline
\end{tabular}

\section{Abbreviations}

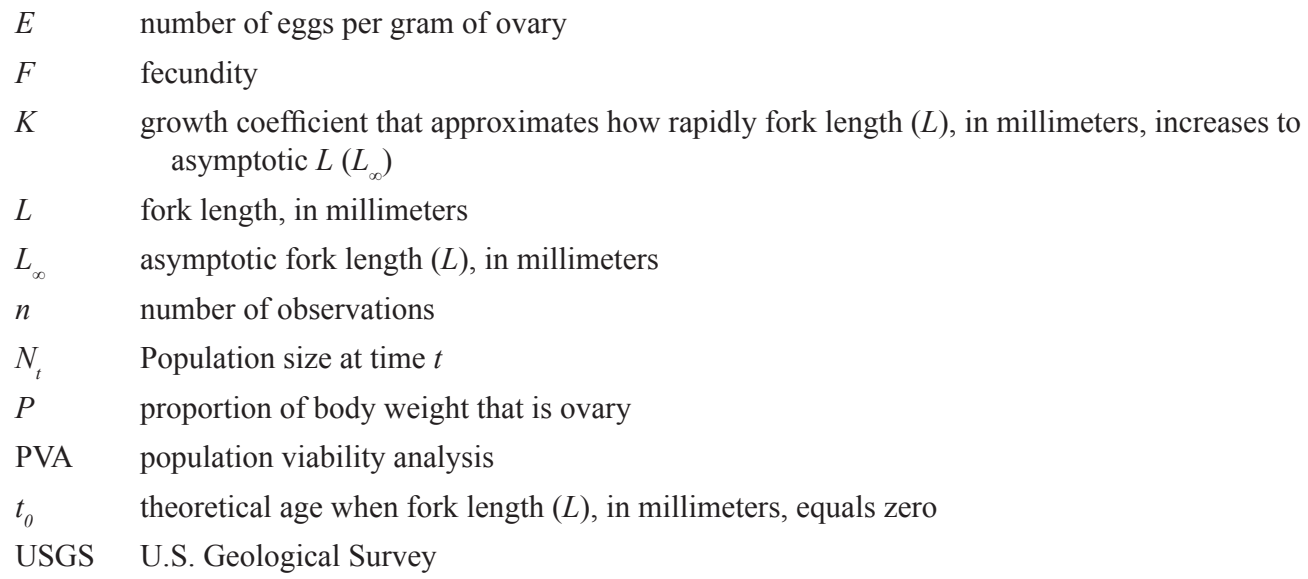




\title{
Visual Basic, Excel-Based Fish Population Modeling Tool-The Pallid Sturgeon Example
}

\author{
Edward H. Moran', Mark L. Wildhaber ${ }^{2}$, Nicholas S. Green², and Janice L. Albers ${ }^{2}$
}

\section{Abstract}

The model presented in this report is a spreadsheet-based model using Visual Basic for Applications within Microsoft Excel (http://dx.doi.org/10.5066/F7057D0Z) prepared in cooperation with the U.S. Army Corps of Engineers and U.S. Fish and Wildlife Service. It uses the same model structure and, initially, parameters as used by Wildhaber and others (2015) for pallid sturgeon. The difference between the model structure used for this report and that used by Wildhaber and others (2015) is that variance is not partitioned. For the model of this report, all variance is applied at the iteration and time-step levels of the model. Wildhaber and others (2015) partition variance into parameter variance (uncertainty about the value of a parameter itself) applied at the iteration level and temporal variance (uncertainty caused by random environmental fluctuations with time) applied at the time-step level. They included implicit individual variance (uncertainty caused by differences between individuals) within the timestep level.

The interface developed for the model of this report is designed to allow the user the flexibility to change population model structure and parameter values and uncertainty separately for every component of the model. This flexibility makes the modeling tool potentially applicable to any fish species; however, the flexibility inherent in this modeling tool makes it possible for the user to obtain spurious outputs. The value and reliability of the model outputs are only as good as the model inputs. Using this modeling tool with improper or inaccurate parameter values, or for species for which the structure of the model is inappropriate, could lead to untenable management decisions. By facilitating fish population modeling, this modeling tool allows the user to evaluate a range of management options and implications. The goal of this modeling tool is to be a user-friendly modeling tool for developing fish population models useful to natural resource managers to inform their decision-making processes; however, as with all population models, caution is needed, and a full understanding of the limitations of a model and the veracity of user-supplied parameters should always be considered when using such model output in the management of any species.

\footnotetext{
${ }^{1}$ National Weather Service.
}

${ }^{2}$ U.S. Geological Survey.

\section{Introduction}

Population viability analysis (PVA) has become a valuable modeling tool to conservation managers because it allows predictions to be made about future population trends in the face of changing environmental conditions and uncertainty about key demographic parameters (Morris and Doak, 2002). The endangered pallid sturgeon (Scaphirhynchus albus), used for this report as a motivating example, is endemic to the turbid waters of the Missouri and Lower Mississippi Rivers (Dryer and Sandvol, 1993; Mayden and Kuhajda, 1997). Since the early 1990s, hatchery-reared juvenile pallid sturgeon spawned from wild broodstock have been stocked in the Lower Missouri River (Huenemann, 2014) in an effort to recover the population. Recovery efforts have included habitat manipulations through periodic flow modifications and specific hydroengineering to potentially improve spawning success of adults and survival of juveniles (U.S. Fish and Wildlife Service, 2003). Progeny of hatcheryorigin fish stocked in 1995-97 have reached sexual maturity (Albers and others, 2013; Wildhaber and Bryan, 2006) and have begun to spawn in the Lower Missouri River (DeLonay and others, 2009).

Bajer and Wildhaber (2007) developed an initial, deterministic age-structured model for pallid sturgeon populations in the Lower Missouri River to complete a PVA. Since their model was published, additional information has been published and much more has been learned about pallid sturgeon population biology. Shuman and others (2011) present length-age relations for all four Recovery Priority Management Areas of the Missouri River. In PVAs, growth of sturgeon is often described by von Bertalanffy growth curves that are empirical relations for estimating length at age (Heppell, 2007; Jager, 2001; Jager and others, 2013; Pine and others, 2001; Velez-Espino and Koops, 2009); this includes pallid sturgeon (Bajer and Wildhaber, 2007; Shuman and others, 2011). Using the von Bertalanffy growth model, Shuman and others (2011) observed that the asymptotic length $\left(L_{\infty}\right)$ increases, and the growth coefficient that approximates how rapidly length $(L)$ increases to $L_{\infty}(K)$ decreases latitudinally, suggesting a latitudinal size gradient and a counter-latitudinal growth gradient. A pallid sturgeon PVA in the Lower Missouri River developed within the last 3 years (Steffensen and others, 2013) used a constant fecundity value 
$(F)$ that eliminated the need for a von Bertalanffy growth model. Other work on sturgeon has shown that $F$ changes with size (Van Eenennaam and Doroshov, 1998; Bruch and others, 2006; Kennedy and others, 2006; Colombo and others, 2007; Imanpoor and others, 2009; Nazari and others, 2009; Albers and others, 2013).

The model and its interface presented here (http:// dx.doi.org/10.5066/F7057D0Z), prepared in cooperation with the U.S. Army Corps of Engineers and U.S. Fish and Wildlife Service, allow the user to investigate for themselves how variations in model assumptions (along with other assumptions) might affect population forecasts of any fish species for which the user has enough data to parameterize the model. A flow chart of the model showing the linkages between the different model inputs and outputs is provided in figure 1. Specifically, the user must be able to provide the following: annual survival rates for each age class, parameters for the von Bertalanffy growth model, parameters for one of three built-in $F$ models, maximum age, age of first spawning, sex ratio (proportion female), and the proportion of females that spawn each year. If values are unknown, then the user can enter a range of suspected values to simulate their effect on population dynamics. The default parameter values of the model are derived from our motivating example, the endangered pallid sturgeon of the Lower Missouri River (Wildhaber and others, 2015).

\section{Modeling Tool Example}

The example that is presented is a Leslie matrix model that simulates only female fish, using Lower Missouri River pallid sturgeon (see Wildhaber and others [2015] for full model description) population dynamics, with variation in parameters applied as variance between iterations and time steps of the model. The model operates with discrete time steps of 1 year. We defined year from January 1 to December 31. Age-0 survival is the survival of fish from spawning to December 31. Within each time step, spawning is calculated before survival. This means that a fish can spawn and die in the same year and that an adult in the last year of life can spawn before it dies. Female fish population is counted on January 1.

\section{Modeling Considerations}

The interface developed for this model (http://dx.doi. org/10.5066/F7057D0Z) is designed to allow the user the flexibility to change model structure, parameter values, and uncertainty separately for every component of the model. This flexibility makes the modeling tool applicable to any fish species for which the user has sufficient information with which to parameterize a model. When the user lacks information, the simplicity of defining model parameters through the graphical user interface can facilitate testing a suspected range of parameter values. Along with this flexibility comes the responsibility of the user to understand enough about the fish species they are trying to model to supply reasonable parameters, uncertainties, and response functions. Like most analytical software, this modeling tool will supply outputs based on the model structure defined by the user. If the parameter values, uncertainty, and/or response functions provided are illegitimate (for example, survival rates less than $[<] 0$ or greater than $[>] 1$ ), the model will provide the user warnings as to such violations before they are used. If the user chooses to ignore the warnings, any output will be questionable at best, or the model may crash. The value and reliability of the model outputs are only as good as the model inputs provided by the user. The choices made by the user not to heed the warnings provided and/or to use model parameters, uncertainty, and/or functions that do not truly represent the species being modeled increase the potential to produce spurious output that could be detrimental to the species if used for making management decisions; for example, if survival rates are overestimated, then the model may predict improving stocks when the reverse is true. Underestimating parameter uncertainty can lead to overconfidence in predicted stock numbers and, therefore, decreased emphasis on management efforts that lead to future population crashes. Suspect results can be obtained by choosing inappropriate model functions; for example, using a constant $F$ rate when $F$ is known to increase with size in a species can lead to model outputs that underestimate population growth.

The potential for erroneous output using this modeling tool is inherent in the flexibility it provides. This modeling tool is designed to facilitate fish population modeling, not provide conclusive results. As with any modeling tool, the results are only as good as the assumptions of the model and the validity of the model parameters supplied by the user. The outputs of a model developed using this modeling tool and the interpretation of the resulting outputs are thus the responsibility of the user. The modeling tool allows the user to evaluate a range of management options and implications.

This modeling tool is intended to provide a user-friendly interface for developing fish population models useful to natural resource managers to inform their decision-making processes. Such population models can be useful for guiding species conservation efforts (Akcakaya and SjogerenGulve, 2000; Van Dyke, 2008). They can be used to provide comparison of populations under different management programs; however, because of limits in knowledge of a species' biology and demographics, such models may not provide accurate population estimates or extinction predictions (Beissinger and Westpahl, 1998; Reed and others, 2002; Van Dyke, 2008). Relative effects of mortality and future stocking plans are exactly the type of management programs that can be evaluated using such a model. But, as with all population models, caution is needed, and a full understanding of their limitations should be used in the management of any species. 


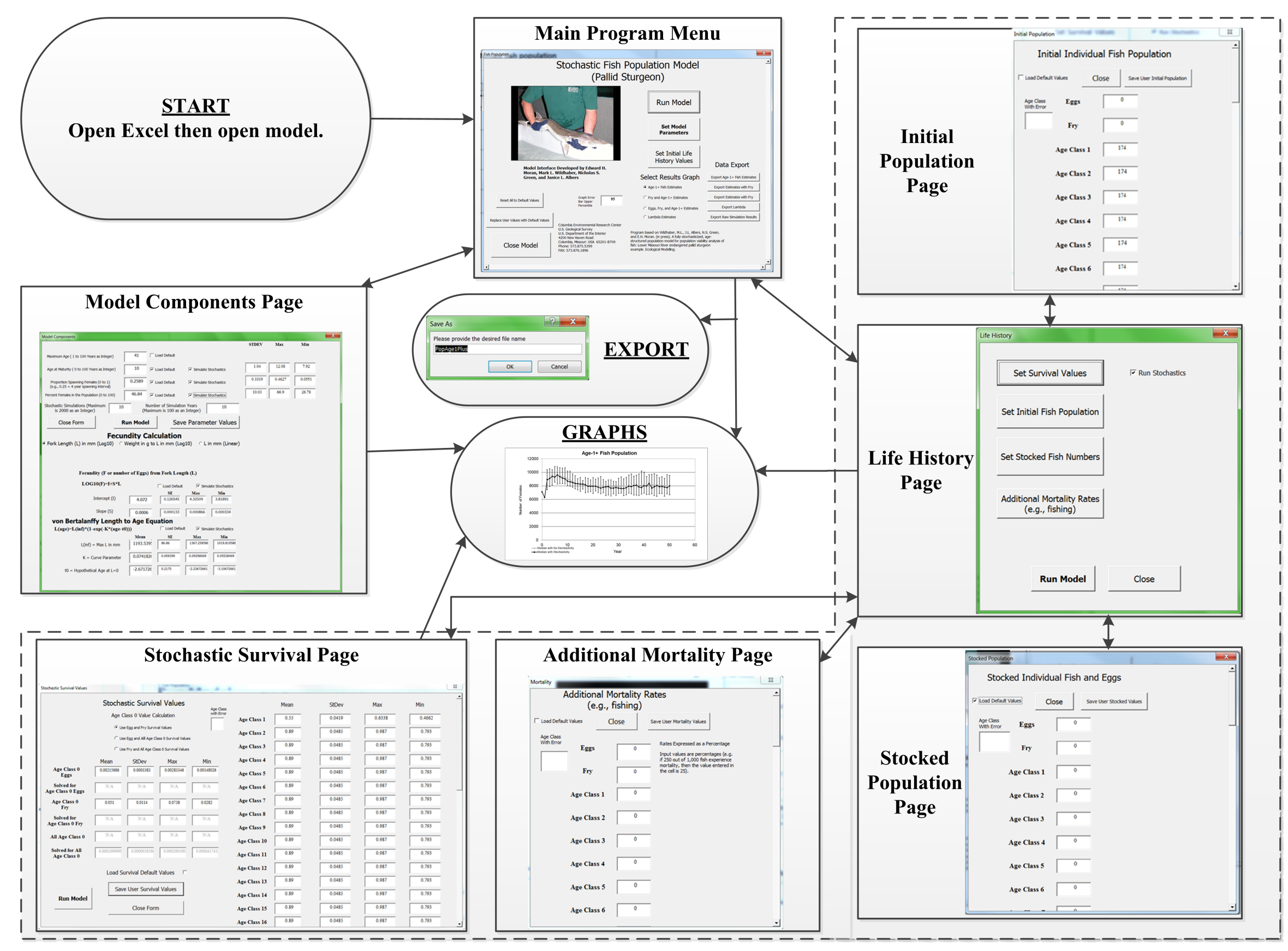

Figure 1. Flow chart of linkages between model inputs and outputs. 


\section{Model Usage}

Instructions for using the Excel-based fish population modeling tool are provided in this section. Open Excel 2010 and maximize screen. Open model file, "Fish_Population Model," using Excel 2010. If your computer has the setting turned on, the file will open in "Protected View," and the user should click "Enable Editing." With the model open, the user should see a graph (fig. 2) and will be taken to the "Fish Population" window (main model page) (fig. 3).

In this "Fish Population" window, there are three main buttons on the right-hand side:

- "Run Model" will run the model with the currently saved parameter values and options. If no user values have been input or stochastic options selected, the model will run with all default values. Graphs displaying results will be automatically generated. The user can select which possible output graphs they would like to see after the model is finished.

- "Set Model Parameters" opens a page where the user will input their own values; and select options for parameters related to growth, reproduction, and maximum age, the number of years and the number of simulations for the model. The model allows the user to save their values for use in future runs, but for those parameters the user changes, the "Load Default" checkboxes must be unchecked for the changes to be saved. All results are saved on model closing, and to avoid overwriting previous results, the user needs to rename the file after it is run.

- "Set Initial Life History Values" will allow the user to change life history values, such as initial population, survival values, mortality rate, and stocking numbers.

Two additional buttons on the "Fish Population" window allow the user to quickly use default values:

- "Reset All to Default Values" will make all parameter values used in the model the default values when pressed.

- "Replace User Values with Default Values" will replace all values that the user has saved with the model's default values.

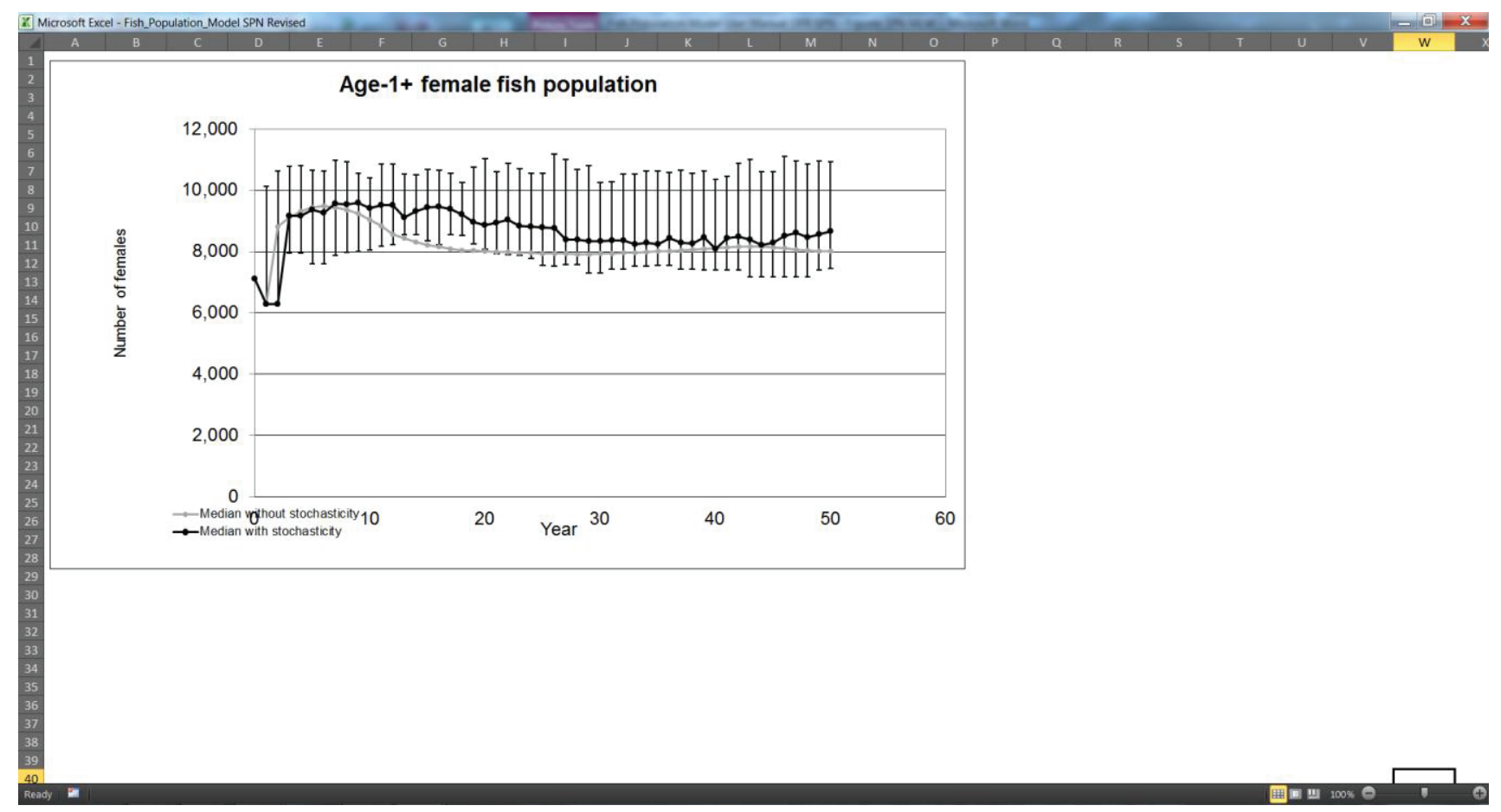

Figure 2. Initial screen on model opening. 


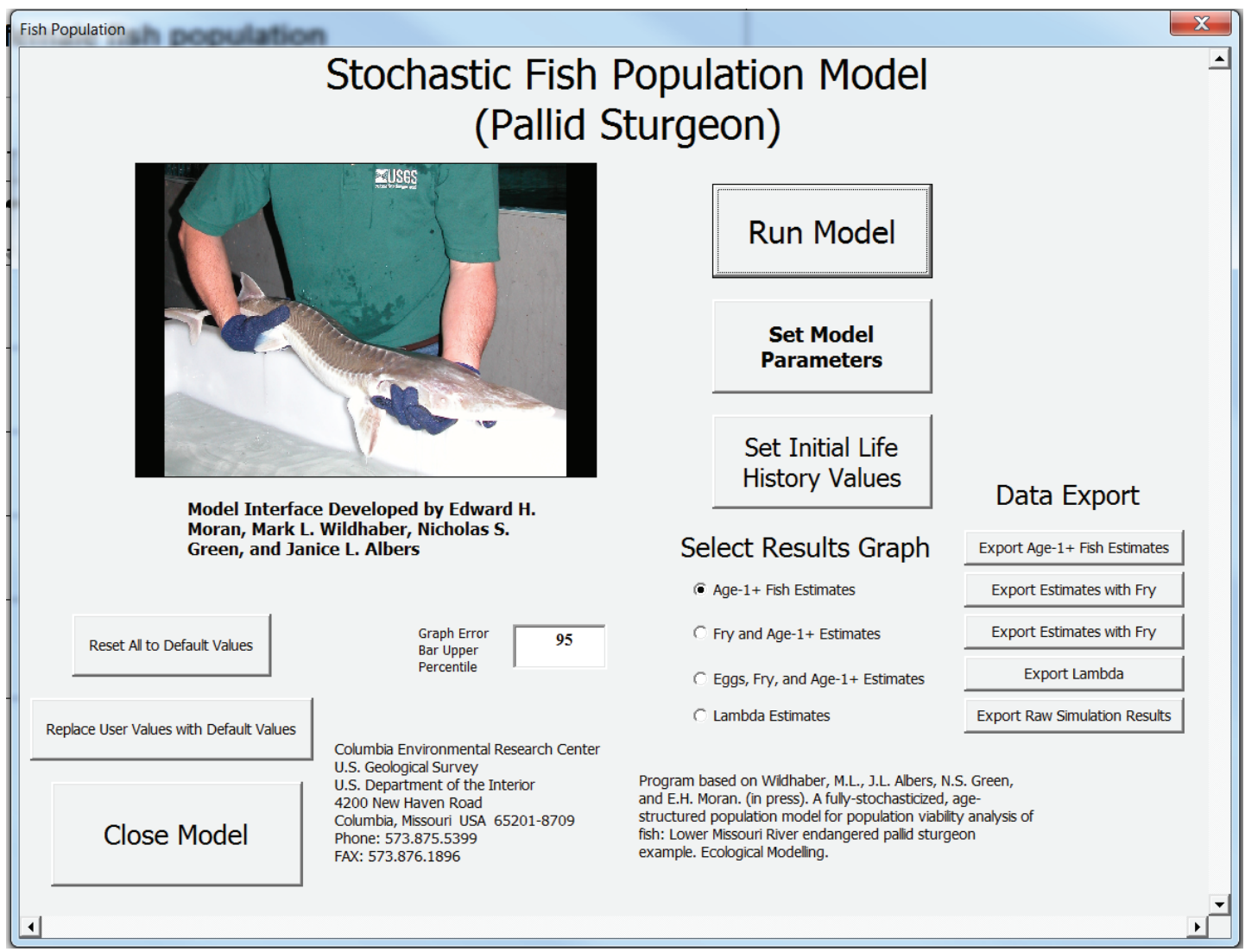

Figure 3. "Fish Population" window (main model page).

\section{Setting Model Parameters}

After clicking on the "Set Model Parameters" button, the "Model Components" window will appear (fig. 4).

This "Model Components" window allows the user to change parameters such as maximum age, age at maturity, spawning intervals, percent of females, $F$, growth, and number of simulations (number of simulations only effects outcome when stochasticity is turned on). If the "Simulate Stochastics" checkbox is checked for a parameter (other than "Maximum Age"), new values will be randomly drawn for each year within a simulation from the distribution defined by default or the user. Below we describe how the user defines the distribution from which these values are drawn for a given year.

The model will warn the user if illegitimate values are entered for some parameters. The $L_{\infty}$ must be greater than or equal to $(\geq) 1$; percent egg mass, percent females, and age of maturity must be between 0 and 100; proportion of females spawning must be between 0 and 1 ; and theoretical age when
$L=0\left(t_{0}\right)$ cannot be positive. Note that the model may still allow the user to save illegitimate values and will attempt to run the model with them; however, if the user ignores the warnings invoked by saving illegitimate values, then the results of the model will be suspect, or the model may crash.

To enter user data in the text cells, uncheck the "Load Default" checkbox for that parameter. Failure to uncheck "Load Default" will cause all user inputs to not be saved even if user clicks the "Save Parameter Values" button and will reset to default upon closing the page. If values other than the default are to be run, uncheck "Load Default" checkbox, input the desired values, and click "Save Parameter Values." If any of the user-supplied values are not legitimate values, warnings will appear. When any form is closed and then reopened, the values in each parameter will be the same as what was set previously, either user or default. Checking and unchecking "Simulate Stochastics" or "Load Default" checkboxes will confirm that user values were saved.

Caution!!! User-input values will not be implemented unless the user clicks "Save Parameter Values." 
Visual Basic, Excel-Based Fish Population Modeling Tool—The Pallid Sturgeon Example

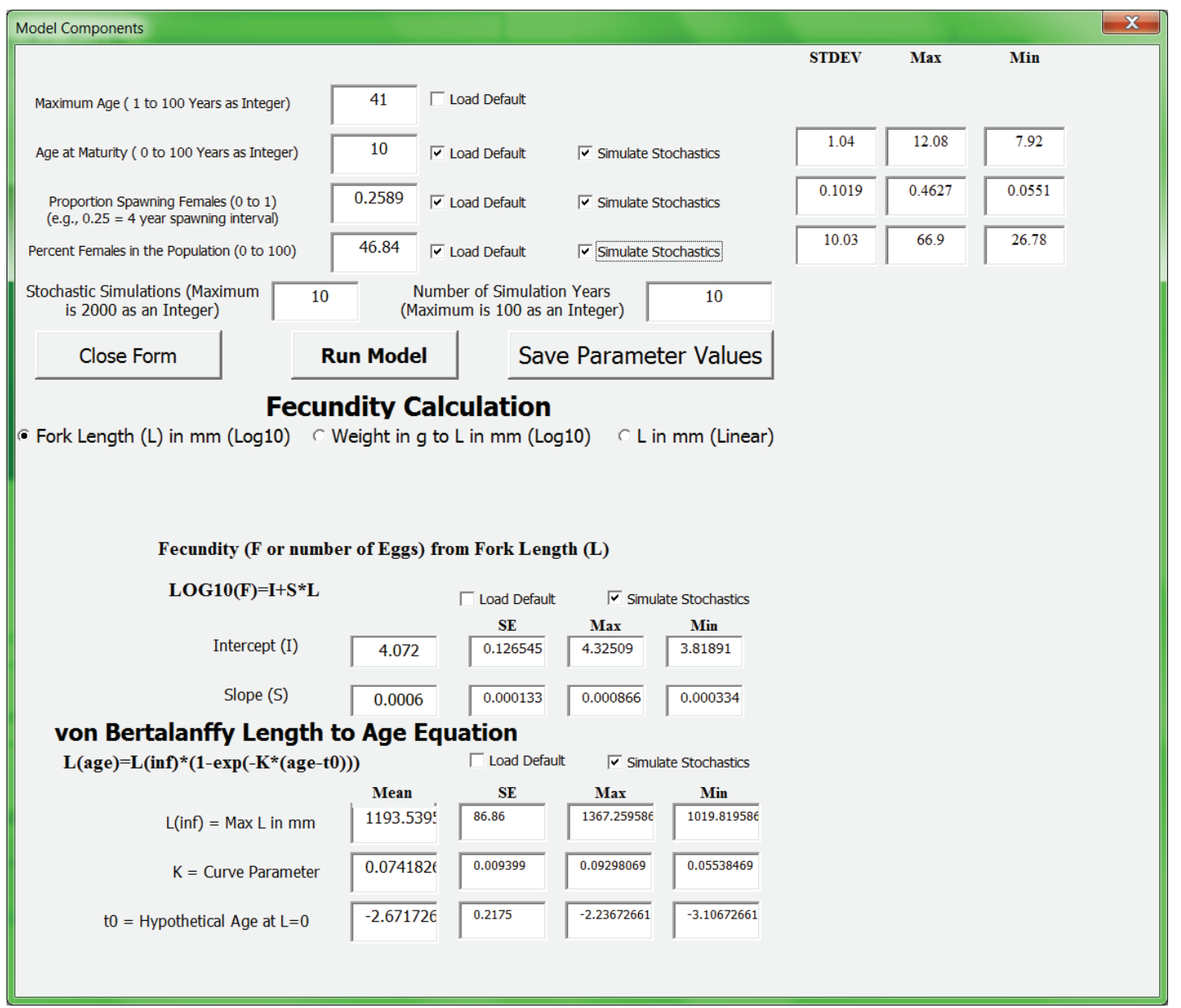

Figure 4. "Model Components" window.

The user can also supply parameters to define the variance of model components on this page. To run the model with stochasticity on a parameter, check the "Simulate Stochastics" checkbox for that parameter. Note that stochasticity can be activated or deactivated for each parameter independently of other parameters and regardless of whether or not the default values are selected. Once the "Simulate Stochastics" checkbox is checked, three boxes will appear. These boxes allow the user to input a standard deviation, minimum, and maximum value for the parameter. The user must supply all three values. These three values, together with the mean, define a truncated normal distribution that will be used to simulate stochastic draws for that model parameter. The user must ensure that they supply a positive standard deviation, a mean that is less than the maximum and greater than the minimum, and a minimum that is less than the maximum. If any of those three conditions are not met, then the user will see a warning. Note that the model may still allow the user to save these values and will attempt to run the model with them. If the user ignores the warnings invoked by saving illegitimate values, then the results of the model will be suspect, or the model may crash.

The four parameters at the top of the "Model Components" window are always used:

- "Maximum Age" parameter--This parameter is the maximum age that an individual can attain in the model. Individuals can survive and reproduce up to this age. Maximum age must be entered as an integer between 1 and 100 .

- "Age of Maturity" parameter-This parameter is the age at which individuals are first able to reproduce. Age of maturity must be entered as a nonnegative integer ( 0 is allowed). Age of maturity can be set to greater than the maximum age with obvious consequences for the simulation results. When age of maturity is set to 0 , only the fry are allowed to reproduce; eggs are not. 
- "Proportion Spawning Females".-This parameter is the proportion of females that spawn in a year, expressed as a proportion between 0 and 1 . This value can also be interpreted as the reciprocal of a spawning interval; for example, a value of 0.25 could mean that individuals spawn once every 4 years, or that in any given year one out of four females will spawn.

- "Percent Females in the Population".--This parameter is the sex ratio, expressed as the percentage of the population that is female. As a percentage, this value must be between 0 and 100 .

Below these four life history parameters are two run characteristics:

- "Stochastic Simulations".--If stochasticity is turned on for any model parameter, this will determine the number of iterations for which the model is run. The user must select between 1 and 2,000 iterations.

- "Number of Simulation Years".-This value defines the number of years for which to simulate population dynamics. The user must enter a value between 1 and 100 years.

There are three buttons in the center of the "Model Components" window:

- "Close Form".- - This button will close the "Model Components" window and return the user to the "Fish Population" window. This button is useful after the user saves parameters on this page and still needs to enter parameters on another page. Note that pressing this button will not automatically save user values.

- "Run Model". - This button will run the model with the currently saved parameter values.

- "Save Parameter Values".--This button will save the values currently in the boxes. When "Save Parameter Values" is pressed, the model will also check that the values in the boxes are legitimate; for example, it will verify that means are less than the maxima and greater than the minima; that proportions are within $[0,1]$ and percentages are within $[0,100]$; and that parameters have the correct sign. If the user attempts to save illegitimate values, warning boxes will appear describing which values need to be corrected. Note that the model may still allow the user to save these values and will attempt to run the model with them. If the user ignores the warnings invoked by saving illegitimate values, then the results of the model will be suspect, or the model may crash.

Below these three buttons are two more sets of life history parameters: "Fecundity Calculation" and "von Bertalanffy Length to Age Equation." Fish growth, or more specifically fish length at age, is determined by a von Bertalanffy growth model. The von Bertalanffy growth model uses the age of a fish to set its length. The user must supply all three parameters of the von Bertalanffy growth model. The $L_{\infty}$ must be positive; $t_{0}$ must be $\leq 0$, and $K$ must be positive. Like sex ratio, age of maturity, and proportion spawning, the user can elect to apply stochasticity to any combination of $L_{\infty}, K$, and $t_{0}$ by supplying a standard deviation, minimum value, and maximum value for each parameter.

The model allows the user to select one of three models to determine $F$, or the number of eggs produced per individual female per year. All three $F$ models depend on the length result of the von Bertalanffy growth model in a slightly different way. Only one $F$ model can be active at a time. The user can select which $F$ model to use by clicking on the appropriate radio button. Once a $F$ model is selected, the appropriate boxes will appear to set its parameters:

- "Fork Length (L) in mm (Log10)".--This option is based on the $F$ structure in Albers and others (2013) and uses a $\log _{10}$-transformed $F$ that depends linearly on fork length $(L)$ in millimeters (equation 1 ).

$$
\log _{10}(F)=\beta_{0}+\beta_{1} \times \mathrm{L},
$$

where

$$
\begin{array}{ll}
F & \text { is the fecundity; } \\
\beta_{0} & \text { is the intercept, } 4.1724 \pm 0.1879 ; \\
\beta_{1} & \text { is the slope, } 0.0005 \pm 0.0002 \text { (Albers and } \\
& \text { others, 2013); and } \\
L & \text { is the fork length. }
\end{array}
$$

Like other parameters, the user can select stochasticity to be applied to the intercept and slope. The user can also set a constant $F$ by setting the slope to 0 and the intercept to the $\log _{10}$ of the desired $F$.

- "Weight in g to L in mm $(\log 10)$ ".- - This option is based on the $F$ structure in Bajer and Wildhaber (2007), which specifies that $F$ depends on a proportion of body weight that is ovary $(P)$, the number of eggs per gram of ovary $(E)$, a power function of body weight in grams $(W)$, where weight varies as a linearized power function of $L$ in millimeters (equation 2).

$$
F=\left(\frac{P}{100}\right) \times E \times 10^{\log _{10}\left(\beta_{0}+\beta_{1} \times \log _{10}(L)\right)},
$$

where

$$
\begin{array}{ll}
F & \text { is the fecundity; } \\
P & \text { is the proportion of body weight that is ovary; } \\
E & \text { is the number of eggs per gram of ovary; } \\
\beta_{0} & \text { is the intercept, }-5.9950 \pm 0.0185 ; \\
\beta_{1} & \text { is the slope, } 3.1873 \pm 0.0067 \text { (number of } \\
& \text { observations }(n)=4,623, r^{2}=0.98, \text { minimum } \\
& \text { length }(L)=152 \text { millimeters }[\mathrm{mm}] \text { and } \\
& \text { maximum } L=1,116 \mathrm{~mm}) .
\end{array}
$$

The default percent body weight of ovary value is estimated to be 15.067 grams (standard deviation=4.438; that is, 
gonadal-somatic index) based on three pallid sturgeon (Keenlyne and others, 1992; George and others, 2012). The default values for the $\log _{10}$ weight (in grams) $-\log _{10} L$ equation were from data collected from the Pallid Sturgeon Population Assessment Program (Wildhaber and others, 2014). Lastly, an estimate of the default $E$ was estimated to be 83.933 (standard deviation=2.914) based on three pallid sturgeon (Keenlyne and others, 1992; George and others, 2012). Like other parameters, the user can select stochasticity to be applied to the intercept and slope, as well as to the $P$ and $E$. The user can also set a constant $F$ by setting the slope to 0 and the intercept to the $\log _{10}$ of the desired $F$.

- "L in mm (Linear)".--This option is based on the $F$ structure in Wildhaber and others (2015) that specifies that $F$ depends linearly on $L$ in millimeters (equation 3 ).

$$
F=\beta_{0}+\beta_{1} \times L
$$

where

$$
\begin{array}{cl}
F & \text { is the fecundity, } \\
\beta_{0} & \text { is the intercept, } \\
\beta_{1} & \text { is the slope, and } \\
L & \text { is the fork length. }
\end{array}
$$

Like other parameters, the user can select stochasticity to be applied to the intercept and slope. Using this option, the user can also apply a uniform, constant $F$ by setting the slope to 0 and the intercept to the constant $F$.

If no other life history parameters need to be changed from the defaults, the model can be run from the "Model Components" window by clicking "Run Model."

Caution!!! Don't forget to click the "Save Parameter Values" button to avoid losing any data!

Caution!!! Before inputting any user data in the text cells, uncheck the "Load Default" checkbox for that parameter. Failure to uncheck "Load Default" checkbox will cause all user inputs to reset to default upon closing or saving the form.

\section{Setting Initial Life History Values}

To set life history values, click the "Set Initial Life History Values" button on the "Fish Population" window (fig. 3) of the model. Then, a new "Life History" window will appear with multiple buttons that open corresponding subwindows (fig. 5). At this time (publication of the report), stochasticity is only implemented for the survival rates.

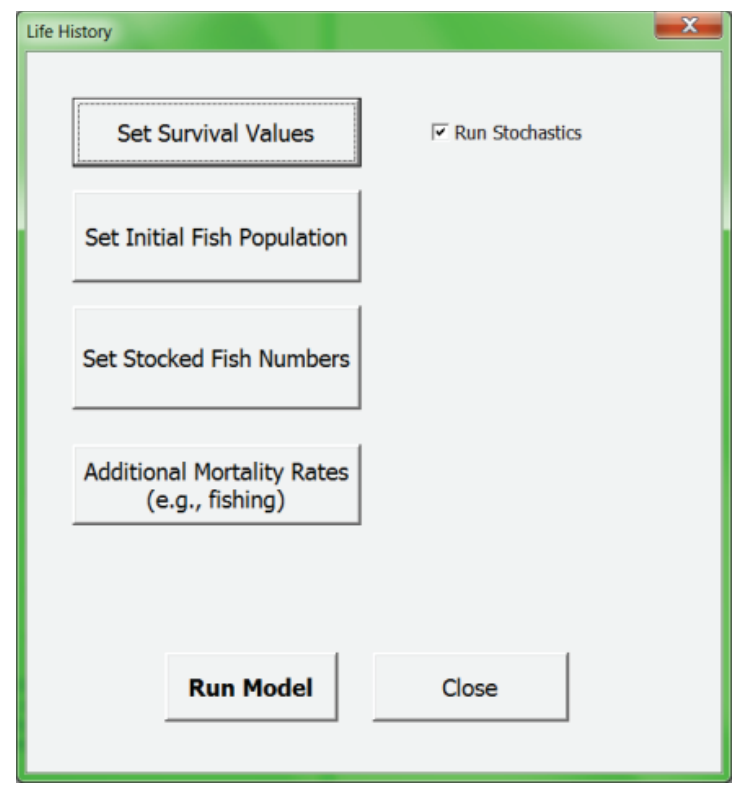

Figure 5. "Life History" window.

These subwindows allow the user to input survival rates, initial population sizes, stocking numbers, and mortality rates, such as natural mortality rates. Upon opening these subwindows through their respective buttons, the user will notice numerous text boxes for Age Class inputs. Notice that the number of age classes corresponds to the "Maximum Age" value that was entered in the upper half of the "Model Components" window; therefore, the user must enter and save their desired maximum age before coming to the "Life History" window or its subwindows.

- "Set Survival Values," with "Run Stochastics" in the "Life History" window (fig. 5) checked, opens the "Stochastic Survival Values" window that is a form to enter survival values with stochasticity (fig. 6).

In this model, survival of the first year of life (that is, age-0 survival) is modeled as the product of two intra-annual survival rates: the survival of eggs to the larval stage ("egg survival") and the survival of larvae or fry to the end of the calendar year ("larval survival"). The user need only input two of these rates; the model will automatically calculate the third. The user can choose which components of age- 0 survival rate to enter by clicking one of the option buttons in the top-left corner. If the user only has a total age- 0 survival estimate, then option 2 or 3 can be selected, and any value can be used for the egg or fry survival. 


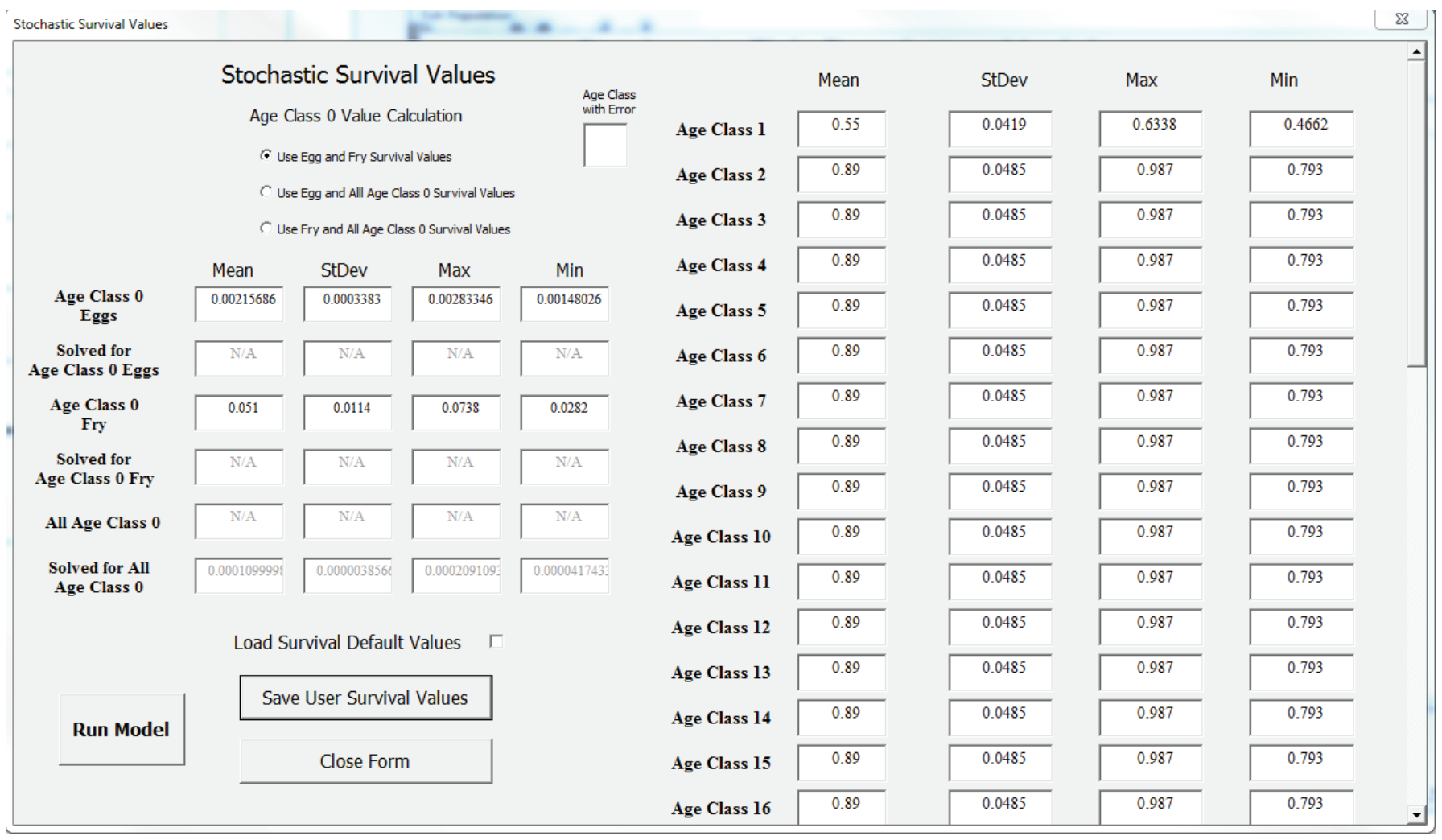

Figure 6. "Stochastic Survival Values" window.

- "Use Eggs and Fry Survival Values".--If the user has an estimate of egg survival (for pallid sturgeon this was survival from spawn to stock age) and fry survival (for pallid sturgeon this was stock age to December 31 of the first year), then they can select "Use Egg and Fry Survival Values" and enter parameters for "Age Class 0 Eggs" and "Age Class 0 Fry." Note all other options are unavailable. Using these two estimates, the model determines the third parameter: "Solved for All Age Class 0."

- "Use Egg and All Age Class 0 Survival Values".--If the user has estimates of survival for the eggs (for pallid sturgeon this was survival from spawn to stock age) and total survival from spawn to December 31 of the first year, then they can select "Use Egg and All Age Class 0 Survival Values" and enter parameters for "Age Class 0 Eggs" and "All Age Class 0." With these two values, the model determines the third parameter: "Solved for Age Class 0 Fry."

- "Use Fry and All Age Class 0 Survival Values".--If the user has estimates of survival for the fry (for pallid sturgeon this was stock age to December 31 of the first year) and total survival from spawn to December 31 of the first year, then they can select "Use Fry and All Age Class 0 Survival Values" and enter parameters for "Age Class 0 Fry" and "All Age Class 0." With these two values, the model determines the third parameter: "Solved for Age Class 0 Eggs." 
With stochasticity checked on, the remaining survival rates, for ages 1 to 1 less than the maximum age, are on the right side of the "Stochastic Survival Values" window. The number of survival rates displayed for input here is dependent on the currently saved value of maximum age; therefore, the user should enter and save their desired maximum age on the "Model Components" window before attempting to enter and save survival rates. Like parameters on the "Model Components" window, the user can input the mean of each age-specific survival rate independently. If stochasticity for survival rates is activated, the user can also enter a standard deviation, maximum, and minimum for each age-specific survival rate. Survival rates are limited to the interval $[0,1]$. Standard deviations must be nonnegative, means must be less than maxima and greater than minima, and for each rate the user must supply a minimum less than the maximum. If any of these four conditions is not met when the user clicks "Save User Survival Values," then a message box will appear stating which condition was violated. The small box near the top center of the "Stochastic Survival Values" window titled "Age Class with Error" will display the age class to which the violation relates after the "OK" button is clicked for the error message. Note that although there is a warning, the model will save an illegitimate value and use it; in that event, the model may produce nonsensical results or crash.

If the user does not want to enter survival estimates, there is a "Load Survival Default Values" checkbox available at the lower center of the "Stochastic Survival Values" window. When this checkbox is checked, the default survival estimates for each age class will populate the form. The user must uncheck this checkbox in order to enter and save their own values for survival estimates.

Caution!!! The user is responsible for inputting concordant values for egg survival, fry survival, and overall age-0 survival rates. Overall age-0 survival rate is the product of the egg and fry survival rates. Failure to input egg, fry, and age-0 survival rates that are consistent with each other will cause the model to produce nonsensical output.

Caution!!! The user must click "Save User Survival Values" after entering survival rates to avoid losing any data.

Caution!!! Before inputting any user data in the text cells, uncheck the "Load Survival Default Values" checkbox for that parameter. Failure to do so will cause all user inputs to reset to default upon closing or saving the form.

Caution!!! The user must reselect the option button in the topleft corner for the type of age class-0 survival rate calculation after unchecking the "Load Survival Default Values" checkbox. If an option button is not selected, the model will use the default survival rates instead of user input rates.

Use the "Close Form" button to exit the page, or click "Run Model" if no additional inputs are needed.

\section{Defining the Initial Population}

The size and age distribution of the initial population can be set on the "Initial Population" window (fig. 7). To access this window, click the "Set Initial Fish Population" button on the "Life History" window (fig. 5). This opens a form where the user can enter the number of fish for the starting population. No stochasticity is allowed for these values. This form has a box for each age class in the model where the user can enter the number of individual females to start the simulation with. As with the survival rates, the number of age classes available on this form is dependent on the currently saved value of maximum age; therefore, the user must enter and save their desired maximum age before coming to the "Life History" window or its subwindow.

If the user does not want to enter initial population size or age distribution, there is a "Load Default Values" checkbox available at the top left of the form. When this checkbox is checked, the default initial population sizes for each age class will populate the form. The user must uncheck this checkbox to enter and save their own values for initial population size.

To save user-entered initial population sizes, click the "Save User Initial Population" button at the top right corner. When this button is pressed, the model will check to make sure that each value on the form is nonnegative. If the user attempts to save a negative initial population size, a warning will appear. The small text box titled "Age Class with Error" will display the age class with the negative population after the "OK" button is clicked (fig. 7). Note that although there is a warning, the model will save an illegitimate value and use it; in that event, the model may produce nonsensical results or crash.

- "Close".-Click to exit the "Initial Population" window when done.

Caution!!! The user must click "Save User Initial Population" after entering initial population sizes to avoid losing any data!

Caution!!! Before inputting any user data in the text cells, unselect the "Load Default Values" checkbox for that parameter. Failure to do so will cause all user inputs to reset to default upon closing or saving the form. 


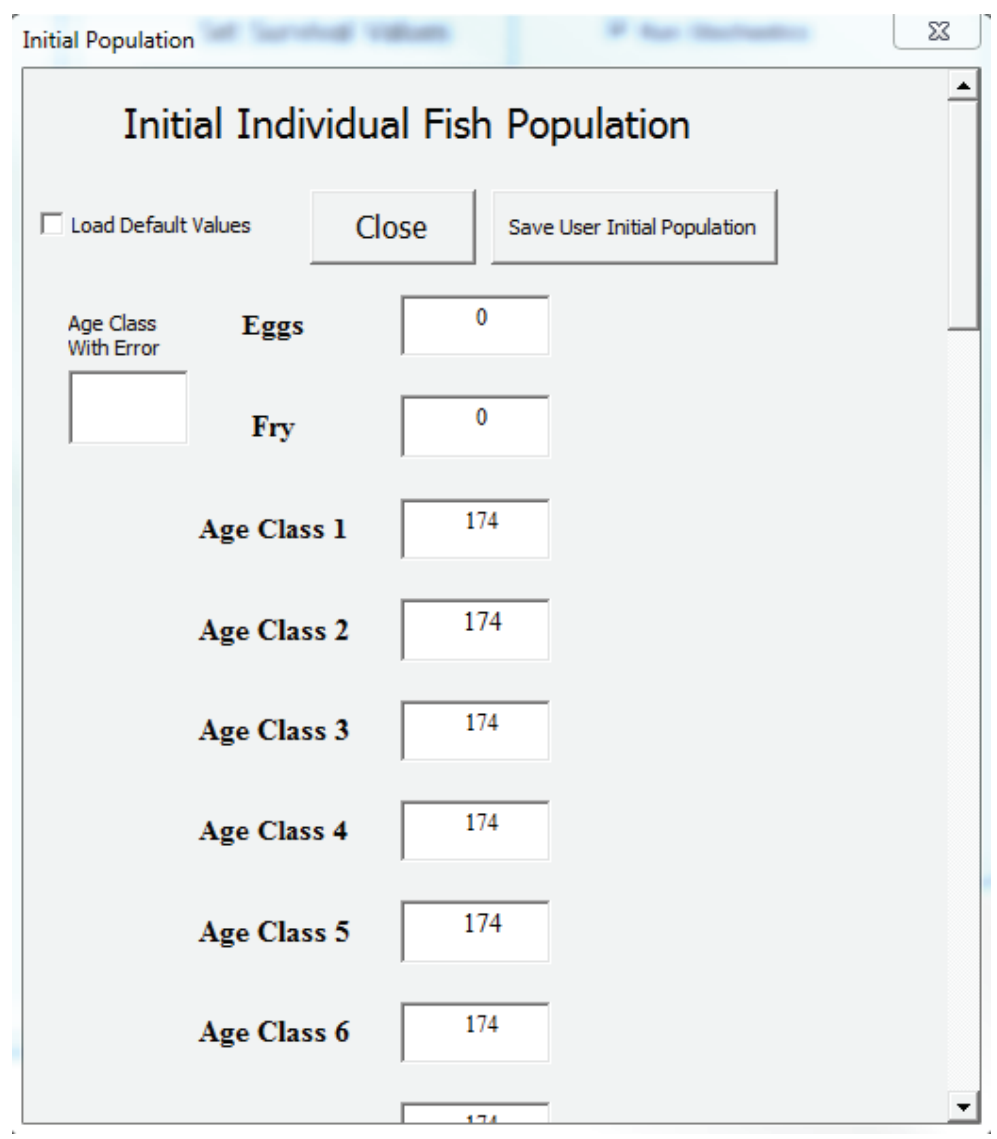

Figure 7. "Initial Population" window.

\section{Setting Stocking Values}

Stocking of any age class in the model can be added in the "Stocked Population" window (fig. 8). To access this window, click the "Set Stocked Fish Numbers" button on the "Life History" window (fig. 5). This opens a form where the user can enter the number of fish to be stocked yearly into any age class. As with the survival rates, the number of age classes available on this form is dependent on the currently saved value of maximum age; therefore, the user must enter and save their desired maximum age before coming to the "Life History" window or its subwindow. No stochasticity is allowed for these values.
The default is for no stocking of any age class. This can be obtained by checking the "Load Default Values" checkbox in the top left of the form. User-defined values can be entered by first unchecking the "Load Default Values" checkbox and then putting the desired number of stocked fish into the box for each age class. As with other parameters, these values must be saved before they are used by clicking the "Save User Stocked Values" button at the top right. When this button is clicked, the model will check for illegitimate negative stocking values and give a warning. The small text box titled "Age Class with Error" will display the age class with the negative value after the "OK" button is clicked. Note that although there is a warning, the model will save an illegitimate value and use it; 


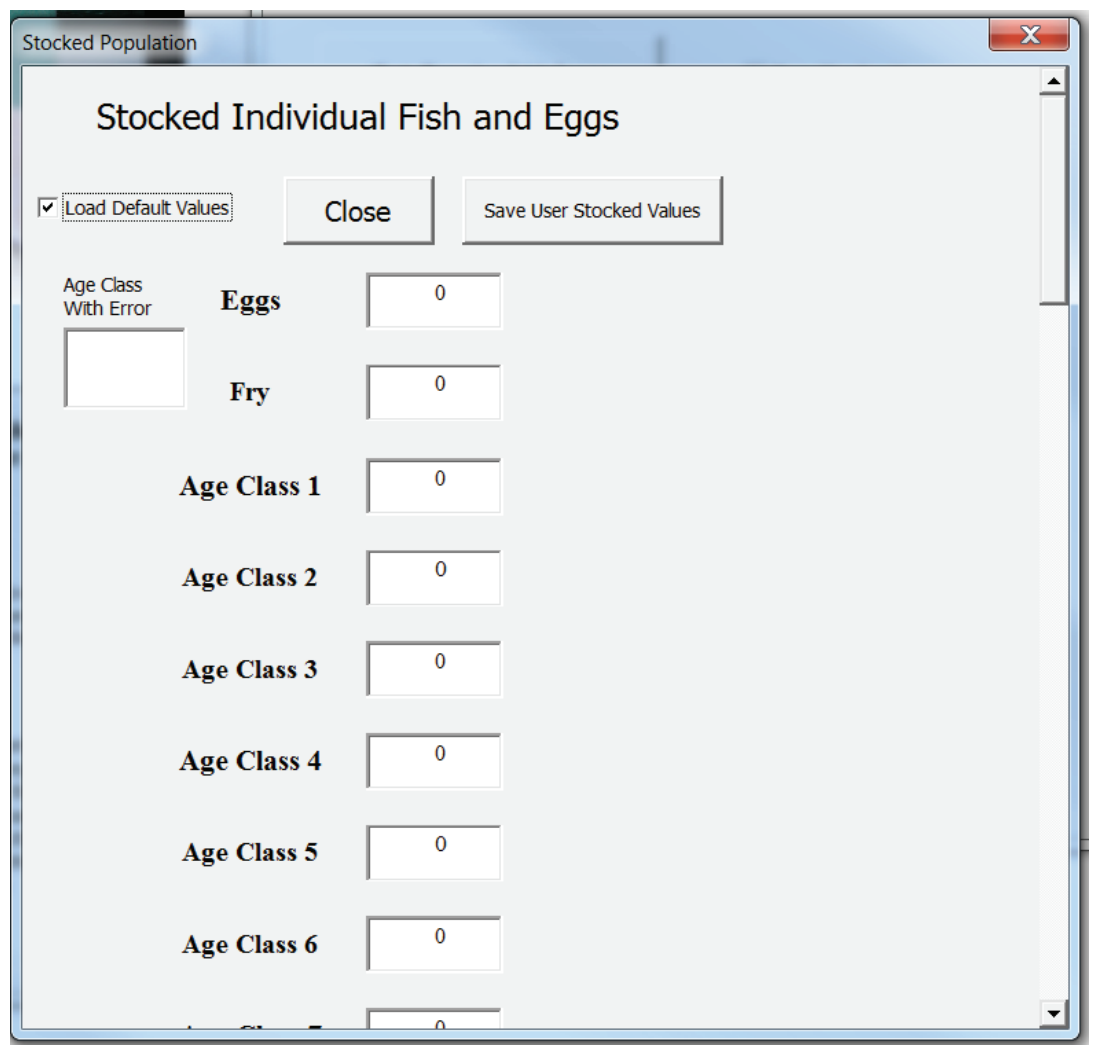

Figure 8. "Stocked Population" window.

in that event, the model may produce nonsensical results or crash. Once user values are entered and saved, click "Close" to close this form and return to the "Life History" window (fig. 5).

- "Close".-Click to exit the window when done.

Caution!!! The user must click "Save User Stocked Values" after entering stocking numbers to avoid losing any data!

Caution!!! Before inputting any user data in the text cells, uncheck the "Load Default Values" checkbox for that parameter. Failure to do so will cause all user inputs to reset to default upon closing or saving the form.

\section{Setting Additional Mortality}

The population model applies a single age-specific survival rate to each age class. An additional mortality rate can be specified for each class to enable modeling of mortality from more than one source. This opens a form where the user can enter additional mortality rates; for example, a population could be simulated where certain age classes experience a natural mortality rate and an additional mortality from another source such as fishing or predation. To enter additional mortality rates (fig. 9), click the "Additional Mortality Rates (e.g., fishing)" button on the "Life History" window (fig. 5). No stochasticity is allowed for these values. As with the survival rates, the number of age classes available on this form is dependent on the currently saved value of maximum age; therefore, the user must enter and save their desired maximum age before coming to the "Life History" window or its subwindow.

Additional mortality is set as a mortality percentage, not a survival rate; for example, if 250 out of 1,000 fish suffer the additional mortality, then the value entered should be 25 . Additional mortality is multiplicative with the main survival rate; for example, if the age- 1 survival rate is set as 0.75 , and the additional mortality for age- 1 is set as 30 , then the resulting age- 1 survival rate is $0.75 \times 0.7=0.525$.

The default is 0 for additional mortality of any age class. This can be obtained by checking the "Load Default Values" checkbox in the top left of the "Mortality" window. Userdefined values can be entered by first unchecking the "Load Default Values" checkbox and then entering the additional mortality into the box for each age class. As with other 


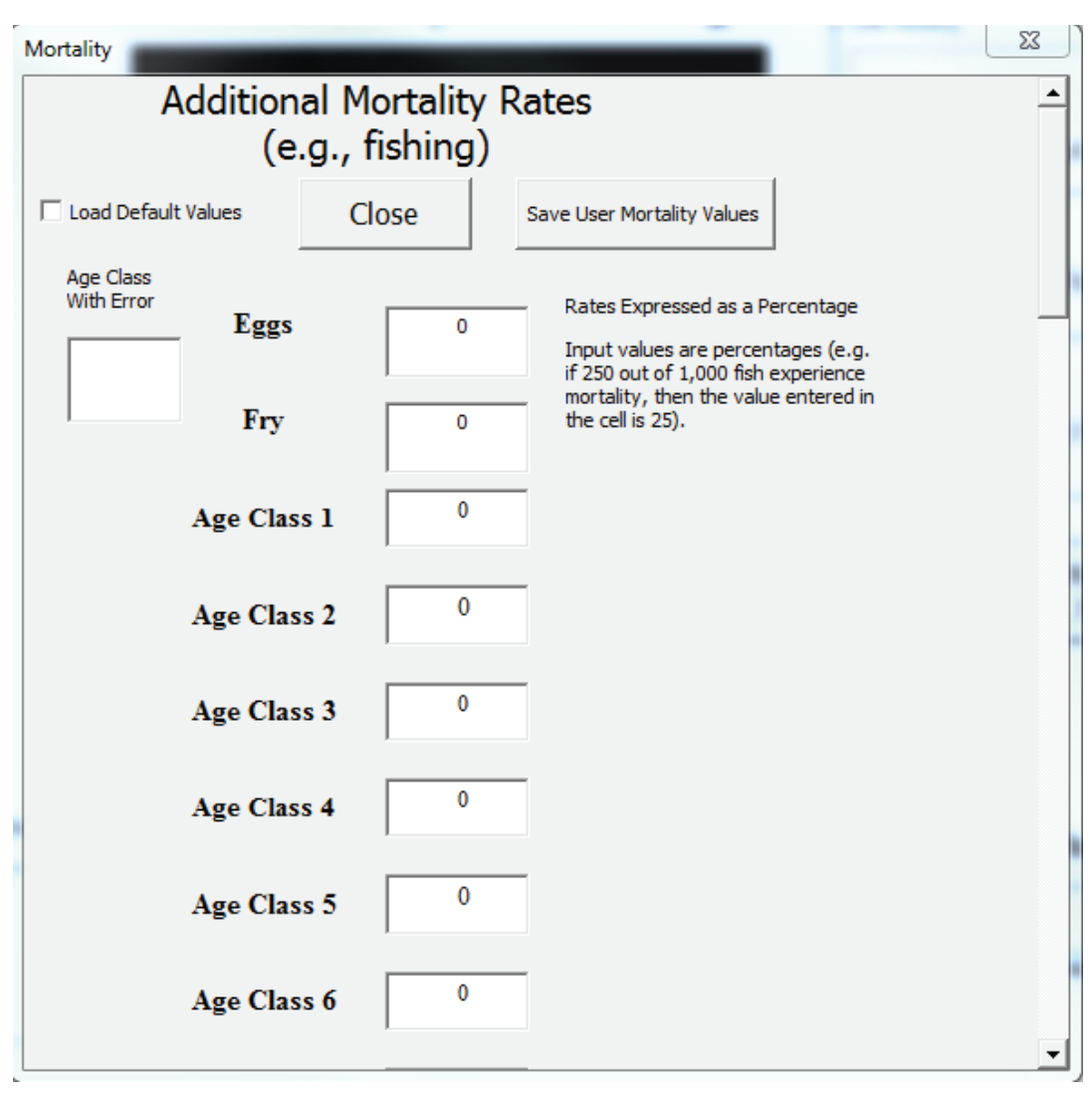

Figure 9. "Mortality" window.

parameters, these values must be saved before they are used by clicking the "Save User Mortality Values" button at the top right. When this button is clicked, the model will check for illegitimate additional mortality values such as those not between 0 and 100. If the user attempts to save a rate outside that interval, a warning will appear. The small text box titled "Age Class with Error" will display the age class with the negative value after the "OK" button is clicked. Note that although there is a warning, the model will save an illegitimate value and use it; in that event, the model may produce nonsensical results or crash. Once user values are entered and saved, click "Close" to close the form and return to the "Life History" window (fig. 5).

Caution!!! The user must click "Save User Mortality Values" after entering additional mortality values to avoid losing any data!
Caution!!! Before inputting any user data in the text cells, uncheck the "Load Default Values" checkbox for that parameter. Failure to do so will cause all user inputs to reset to default upon closing or saving the form.

Once all required inputs are entered into the "Life History" window and subpages, the user can run the model using any of the "Run Model" buttons or using the "Close" button to back out to the main page and clicking the "Run Model" button (fig. 3). After clicking on the "Run Model" button, the progress of the simulations will be projected into the bottom left corner of the screen (fig. 10).

After the simulations are complete, a time window will appear that reports the time it took to run the simulations. Click "OK” (fig. 11).

Another window will appear reporting that the simulations are finished. Click "OK" (fig. 12).

\section{1 Sheet4 Sheet3 Sheet2 Sheet1/Main \\ Please be patient...41 of 45 years done. 1 of 4 simulation.}

Figure 10. Status bar reporting model progress. 


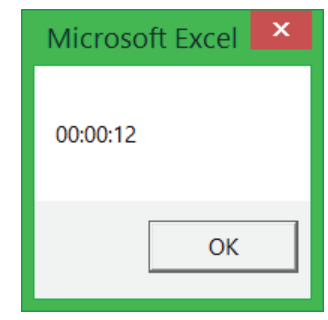

Figure 11. Notification that the simulations have completed and how long they took to run.

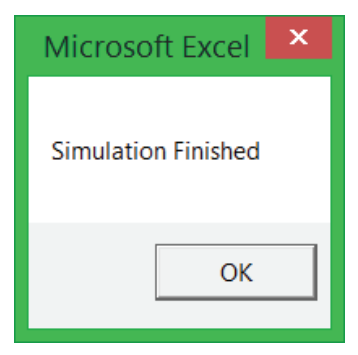

\section{Outputs}

The results of the population simulation are presented in four different graphs: "Age-1+ Fish Estimates," "Fry and Age-1+ Estimates," "Egg, Fry, and Age-1+ Estimates," and "Lambda Estimates." These can be selected in the bottom right corner of the "Fish Population" window (fig. 3).

Additionally, the user can determine what percentile the error bars represent by entering the value into the "Graph Error Bar Upper Percentile" box, where the 50th percentile will show no error bars, and the default value is 95 , which shows the 95 percentile interval (that is, from the 2.5 to 97.5 percentiles).

The first graph, "Age-1+ Fish Estimates," is annual median female population sizes of age-1+ individuals with and without stochasticity. The deterministic model result is shown in grey and the stochastic result is shown in black. The stochastic results are plotted as the median across all iterations, with the percentile interval chosen by the user (fig. 13).

Figure 12. Final notification that the simulations have completed.

\section{Age-1+ female fish population}

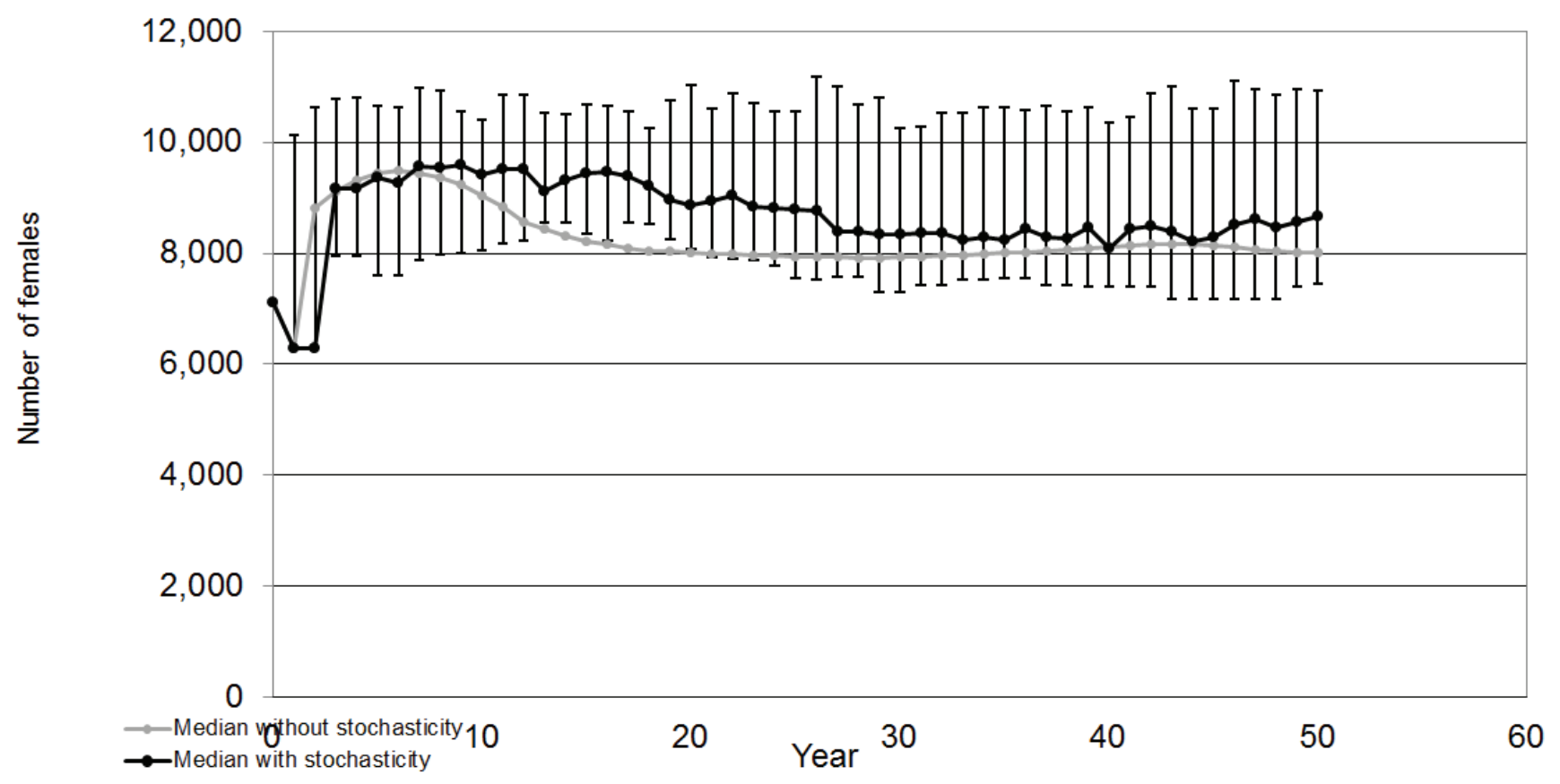

Figure 13. Age-1+ female population numbers. Default values were used with stochasticity applied to age at maturity, proportion of females spawning, and proportion of females in the population. The stochastic simulation was run using a 50-year period with 25 iterations. 
The second graph, "Fry and Age-1+ Estimates," is annual median female population sizes of age-1+ individuals plus fry with and without stochasticity. The deterministic model result is shown in grey and the stochastic result is shown in black. The stochastic results are plotted as the median across all iterations, with the percentile interval chosen by the user (fig. 14).

The third graph "Egg, Fry, and Age-1+ Estimates," is annual median female population sizes of age-1+ individuals plus fry and eggs (that is, age-1+ added to fry count plus egg count) with and without stochasticity. The deterministic model result is shown in grey and the stochastic result is shown in black. The stochastic results are plotted as the median across all iterations with the percentile interval chosen by the user (fig. 15).
The fourth graph, "Lambda Estimates," is annual median female population growth rate, lambda $(\lambda)$. Here, $\lambda$ is calculated as $N / N_{t-1}$ where $N_{t}$ is current number of individuals in the population and $N_{t-1}$ is the number of individuals in the population in the previous year. When $\lambda=1$, the population is stable; $\lambda>1$ signifies population growth, whereas $\lambda<1$ signifies population decline (fig. 16).

To export simulation data and the summary data used to construct the graphs, click the export button next to the radio button that selects that set of results (fig. 3). A "Save As" window will appear where the desired file name can be entered or the user can use the descriptive name for each set of results prepopulated in this window (fig. 17).

When "OK" is clicked, another window will appear showing that the results have been successfully exported (fig. 18).

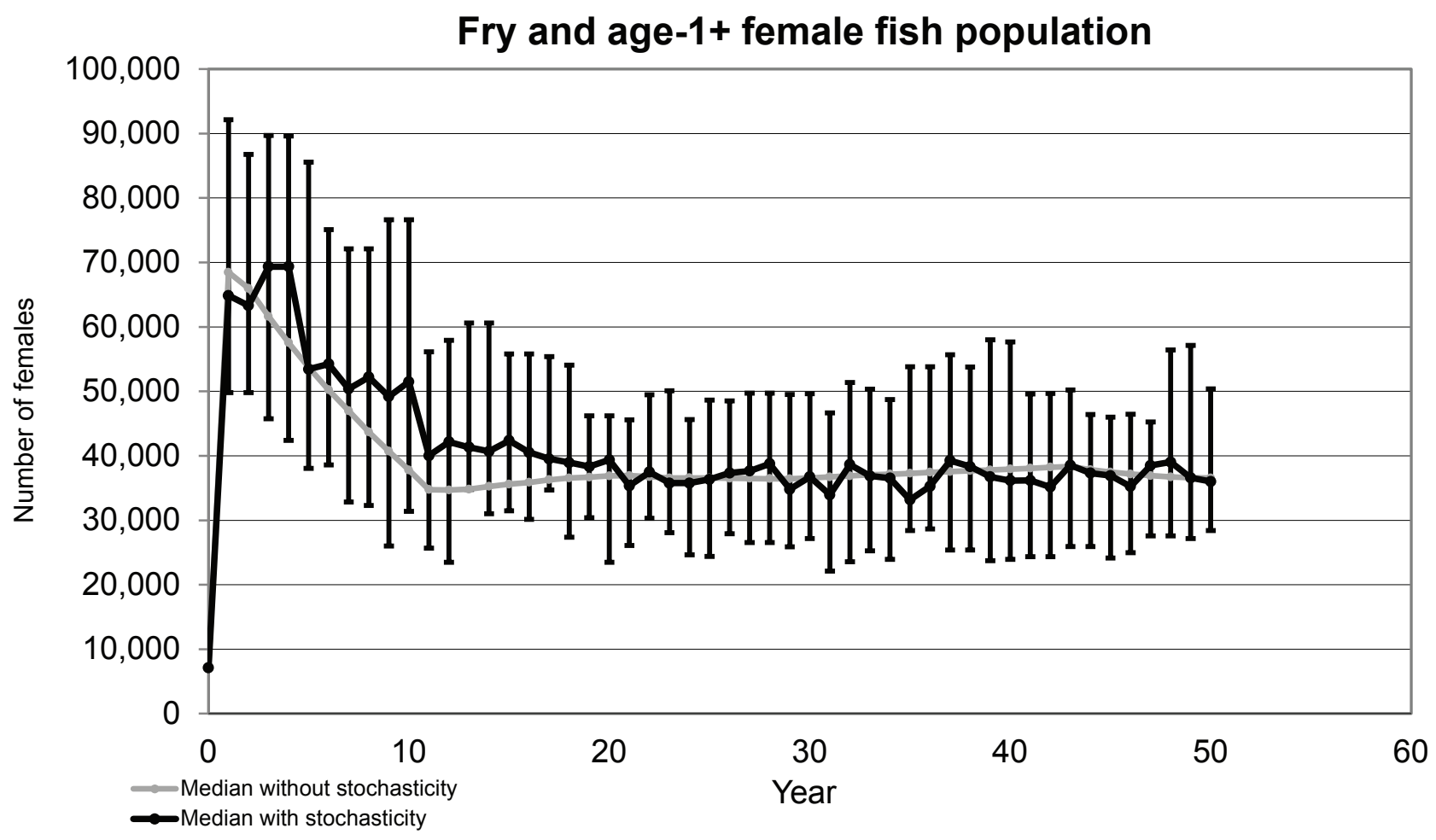

Figure 14. Fry and age-1+ female population numbers combined. Default values were used with stochasticity applied to age at maturity, proportion of females spawning, and proportion of females in the population. The stochastic simulation was run using a 50 -year period with 25 iterations. 


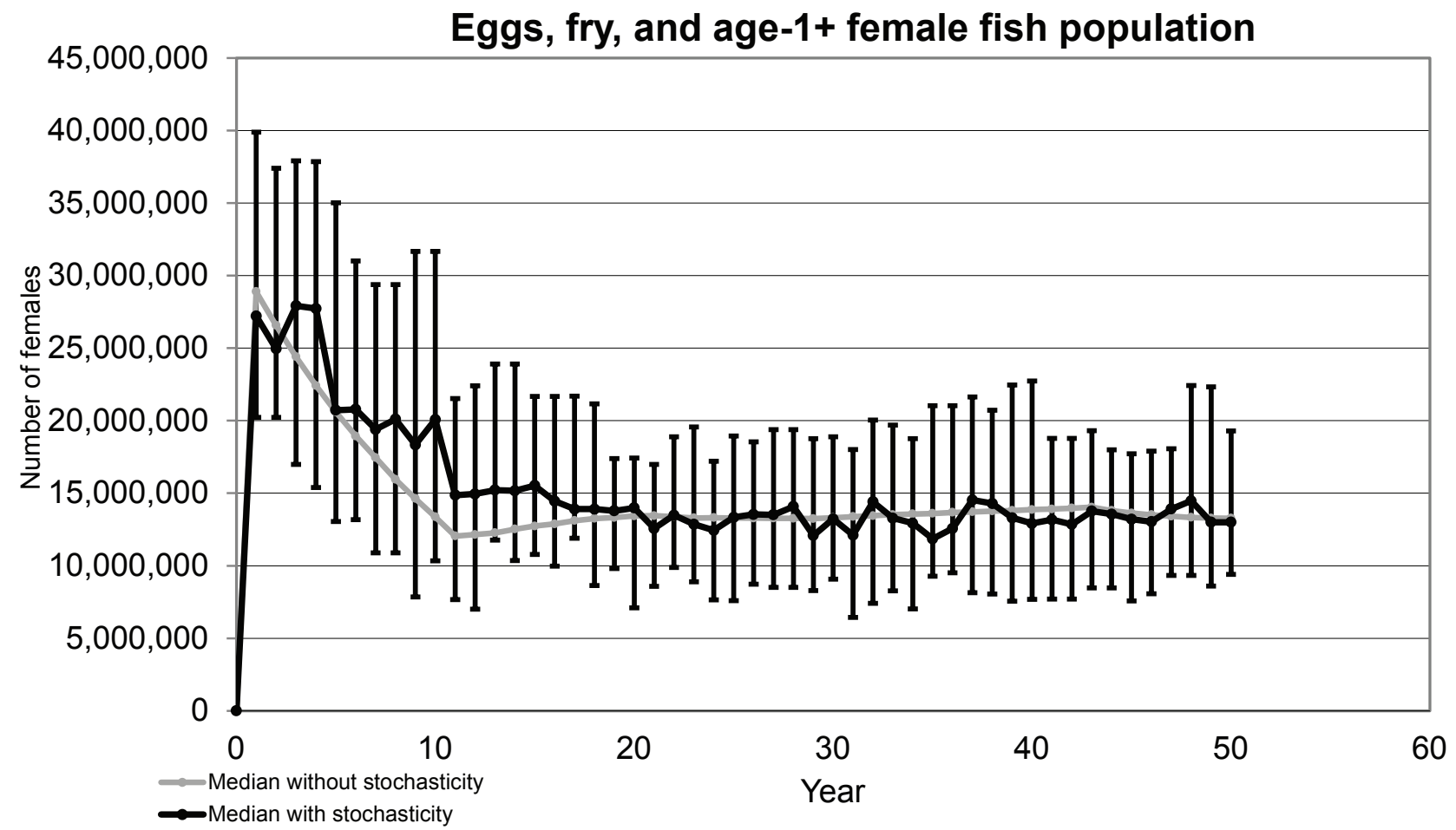

Figure 15. Egg, fry, and age-1+ female population numbers combined. Default values were used with stochasticity applied to age at maturity, proportion of females spawning, and proportion of females in the population. The stochastic simulation was run using a 50 -year period with 25 iterations.

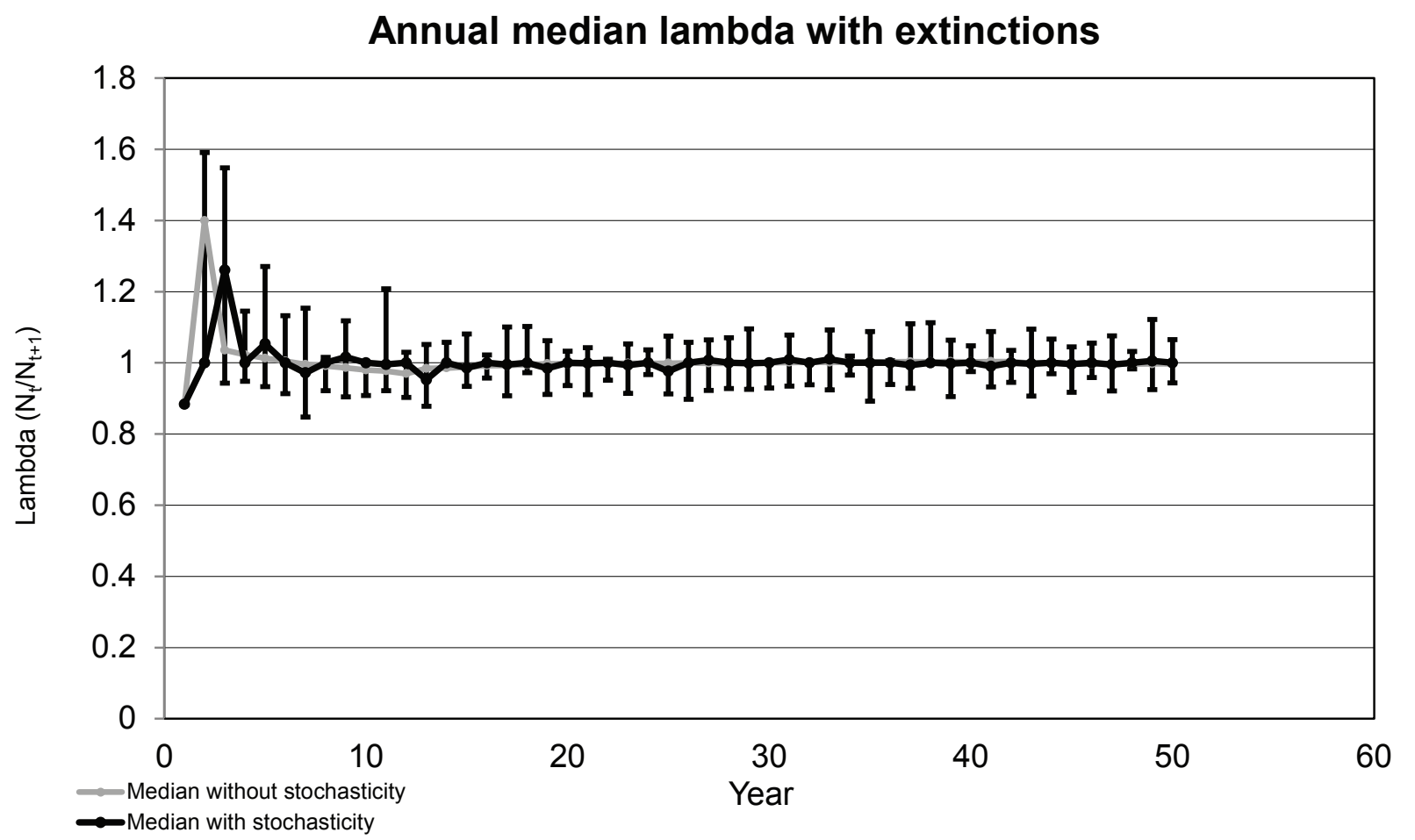

Figure 16. Annual median lambda with extinctions. Default values were used with stochasticity applied to age at maturity, proportion of females spawning, and proportion of females in the population. The stochastic simulation was run using a 50-year period with 25 iterations. 


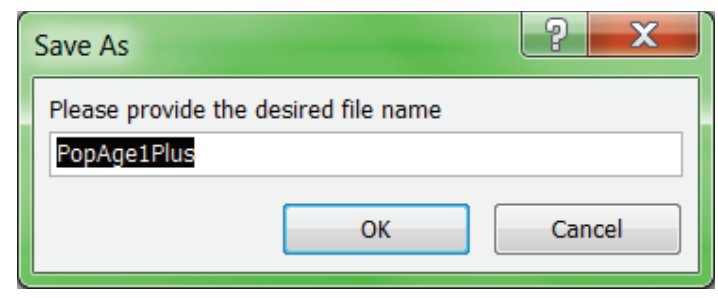

Figure 17. "Save As" window.

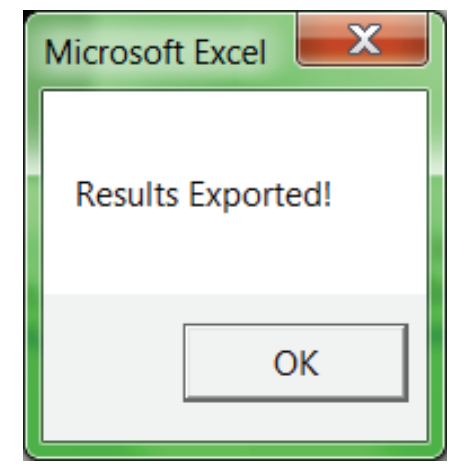

Figure 18. "Results Exported!" completion notice window.
Two files will be saved in the same folder where the model file is saved:

1. The first file is a .xlsm file (a Microsoft Excel workbook) that contains two sheets, which are named for and contain the deterministic and stochastic female population results (fig. 19). The deterministic results have two columns, "Year" and either "Population" (the number of females) or "Lambda" (the population growth rate). If worksheet tabs and scroll bars are missing, then the user needs to turn on these options by selecting "File," "Options," and "Advanced." Under the section called "Display options for this workbook," check the checkboxes for "Show horizontal scroll bar," "Show vertical scroll bar," and "Show sheet tabs."

The stochastic sheet contains a row for each iteration ("simulation"), and the columns represent each year of the simulation (fig. 20).

2. The second file is a .jpg file containing the graph of interest and can be opened using any picture software (for example, Paint ${ }^{\circledR}$, Photo Gallery ${ }^{\circledR}$, and other similar programs) (fig. 21).

\begin{tabular}{|c|c|c|c|c|c|c|c|c|c|}
\hline \multicolumn{8}{|c|}{ R. Microsoft Excel - PopAge1Plus } & \multicolumn{2}{|c|}{\begin{tabular}{|l|l|l|}
$口$ & $\square$ & $X$ \\
\end{tabular}} \\
\hline$\Delta$ & A & B & $\mathrm{C}$ & $\mathrm{D}$ & $\mathrm{E}$ & $\mathrm{F}$ & G & $\mathrm{H}$ & $1 \frac{10}{4}$ \\
\hline 1 & Year & Population & & & & & & & $\equiv$ \\
\hline 2 & ( & 7122 & & & & & & & \\
\hline 3 & 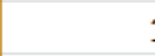 & 6090 & & & & & & & \\
\hline 4 & 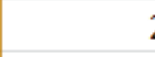 & 3316826 & & & & & & & \\
\hline 5 & 3 & 4756518 & & & & & & & \\
\hline 6 & 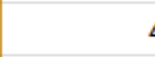 & \begin{tabular}{l|l}
4 & 5843689
\end{tabular} & & & & & & & \\
\hline 7 & 5 & 6623010 & & & & & & & \\
\hline 8 & ( & 7150934 & & & & & & & \\
\hline 9 & 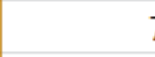 & 7482654 & & & & & & & \\
\hline 10 & 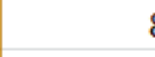 & 7645864 & & & & & & & \\
\hline 11 & 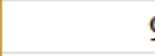 & 7671690 & & & & & & & \\
\hline 12 & 1( & 7587845 & & & & & & & 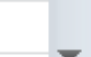 \\
\hline 121 & $\|^{H N 1 / n} \mathrm{~N}$ & $\begin{array}{l}4 n, / n \\
n \text {-Stochasti }\end{array}$ & Sto & & 0 & & III & & II \\
\hline
\end{tabular}

Figure 19. Deterministic spreadsheet data saved. 


\begin{tabular}{|c|c|c|c|c|c|c|c|c|c|c|}
\hline \multicolumn{9}{|c|}{ Microsoft Excel - PopAge1Plus } & \multicolumn{2}{|c|}{$\begin{array}{ll} & \text { 口 } \\
\end{array}$} \\
\hline 4 & A & B & C & D & $\mathrm{E}$ & $\mathrm{F}$ & G & $\mathrm{H}$ & 1 & $\square$ \\
\hline 1 & & |Year & Year & Year & Year & Year & Year & Year & Year & $r$ \\
\hline 2 & Simulation & 0 & 1 & 2 & 3 & 4 & 5 & 6 & 7 & \\
\hline 3 & $\operatorname{Sim} 1$ & 1740 & 1304 & 1068 & 824 & 650 & 493 & 356 & 249 & \\
\hline 4 & $\operatorname{Sim} 2$ & 1740 & 1345 & 1102 & 857 & 688 & 515 & 380 & 270 & \\
\hline 5 & $\operatorname{Sim} 3$ & 1740 & 1351 & 1108 & 862 & 691 & 534 & 418 & 318 & $\equiv$ \\
\hline 6 & $\operatorname{Sim} 4$ & 1740 & 1302 & 1079 & 826 & 679 & 512 & 372 & 265 & \\
\hline 7 & $\operatorname{Sim} 5$ & 1740 & 1321 & 1080 & 847 & 652 & 498 & 366 & 265 & \\
\hline 8 & $\operatorname{Sim} 6$ & 1740 & 1342 & 1089 & 849 & 643 & 492 & 375 & 257 & \\
\hline 9 & $\operatorname{sim} 7$ & 1740 & 1336 & 1089 & 862 & 653 & 510 & 376 & 264 & \\
\hline 10 & $\operatorname{Sim} 8$ & 1740 & 1313 & 1081 & 878 & 682 & 510 & 363 & 253 & \\
\hline 11 & $\operatorname{Sim} 9$ & 1740 & 1375 & 1108 & 885 & 717 & 548 & 405 & 303 & \\
\hline 12 & Sim 10 & 1740 & 1321 & 1081 & 864 & 691 & 504 & 359 & 257 & \\
\hline 13 & & & & & & & & & & \\
\hline 14 & & & & & & & & & & $\nabla$ \\
\hline 14 & 11 & n-Stochastic & Stochas & stic Sheet & $3<$ & 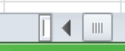 & & & DII & i) \\
\hline
\end{tabular}

Figure 20. Stochastic spreadsheet data saved.

\section{Age-1+ female fish population}

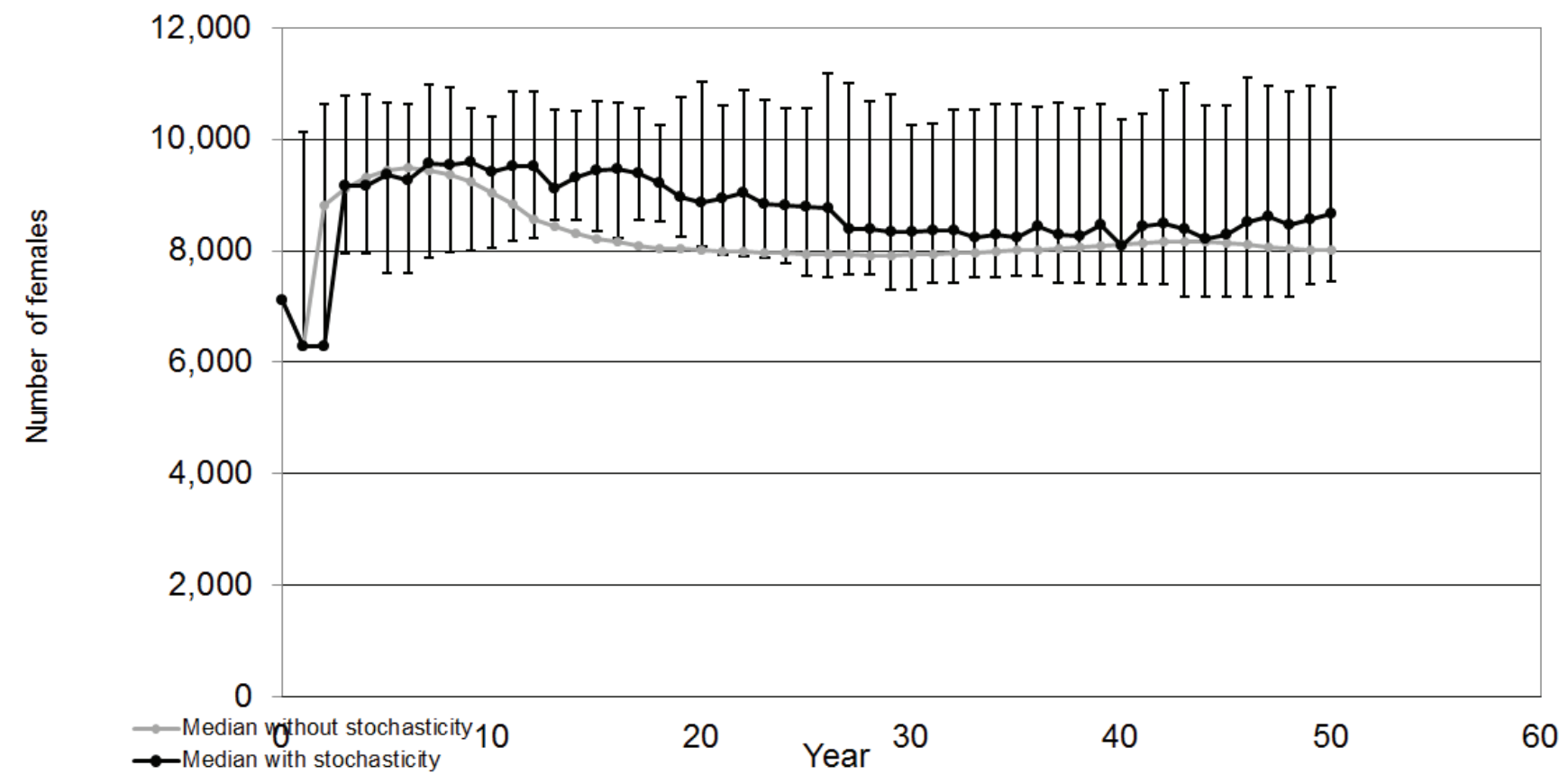

Figure 21. Age-1+ population saved figure. 


\section{Closing and Saving}

To close model, click the "Close Model" button on the main model page (fig. 3). All changes are automatically saved as the same file upon model closing; to avoid overwriting previous results the user needs to rename the file after it is closed, or make a new copy with a changed name before opening the file. Excel security settings such as the "Protected View" are implemented for every new file; therefore, any moved or renamed file will require initial opening and closing before using as was required with first opening of the model.

\section{References Cited}

Akçakaya, H.R., and Sjögren-Gulve, P., 2000, Population viability analyses in conservation planning-An overview: Ecological Bulletins, no. 48, p. 9-21. [Also available at http://www.jstor.org/stable/20113245.]

Albers, J.L., Wildhaber, M.L., and DeLonay, A.J., 2013, Gonadosomatic index and fecundity of Lower Missouri and Middle Mississippi River endangered pallid sturgeon estimated using minimally invasive techniques: Journal of Applied Ichthyology, v. 29, no. 5, p. 968-977. [Also available at http://dx.doi.org/10.1111/jai.12231.]

Bajer, P.G., and Wildhaber, M.L., 2007, Population viability analysis of Lower Missouri River shovelnose sturgeon with initial application to the pallid sturgeon: Journal of Applied Ichthyology, v. 23, no. 4, p. 457-464. [Also available at http://dx.doi.org/10.1111/j.1439-0426.2007.00879.x.]

Bessinger, S.R., and Westpahl, M.I., 1998, On the use of demographic models of population viability in endangered species management: Journal of Wildlife Management, v. 62, no. 3, p. 821-841. [Also available at http://www.jstor. org/stable/3802534.]

Bruch, R.M., Miller, Glenn, Hansen, M.J., 2006, Fecundity of lake sturgeon (Acipenser fulvescens, Rafinesque) in Lake Winnebago, Wisconsin, USA: Journal of Applied Ichthyology, v. 22, no. supplement 1, p. 116-118. [Also available at http://dx.doi.org/10.1111/j.14390426.2007.00938.x.]

Colombo, R.E., Garvey, J.E., and Wills, P.S., 2007, Gonadal development and sex-specific demographics of the shovelnose sturgeon in the Middle Mississippi River: Journal of Applied Ichthyology, v. 23, no. 4, p. 420-427. [Also available at http://dx.doi.org/10.1111/j.14390426.2007.00885.x.]
DeLonay, A.J., Jacobson, R.B., Papoulias, D.M., Simpkins, D.G., Wildhaber, M.L., Reuter, J.M., Bonnot, T.W., Chojnacki, K.A., Korschgen, C.E., Mestl, G.E., and Mac, M.J., 2009, Ecological requirements for pallid sturgeon reproduction and recruitment in the Lower Missouri River-A research synthesis 2005-08: U.S. Geological Survey Scientific Investigations Report 2009-5201, 59 p. [Also available at http://pubs.usgs.gov/sir/2009/5201/.]

Dryer, M.P., and Sandvol, A.J., 1993, Pallid sturgeon (Scaphirhynchus albus) recovery plan: Bismarck, N. Dak., U.S. Fish and Wildlife Service, 55 p.

George, S.G., Slack, W.T., and Hoover, J.J., 2012, A note on the fecundity of pallid sturgeon: Journal of Applied Ichthyology, v. 28, no. 4, p. 512-515. [Also available at http://dx.doi.org/10.1111/j.1439-0426.2011.01931.x.]

Heppell, S.S., 2007, Elasticity analysis of green sturgeon life history: Environmental Biology of Fishes, v. 79, no. 3, p. 357-368. [Also available at http://dx.doi.org/10.1007/ s10641-006-9052-1.]

Huenemann, T.W., 2014, Central Lowlands and Interior Highlands pallid sturgeon spawning and stocking summary 1992-2013: Report to the Middle Basin Pallid Sturgeon Workgroup, $105 \mathrm{p}$.

Imanpoor, M.R., Alavi, S.H., and Cosson, Jacky, 2009, Relationship between biological characteristics of eggs and female brood stocks of Persian sturgeon Acipenser persicus - A comparison with other fish species: Fish Physiology and Biochemistry, v. 35, no. 4, p. 701-709. [Also available at http://dx.doi.org/10.1007/s10695-0099330-x.]

Jager, H.I., Van Winkle, Webster, Chandler, J.A., Lepla, K.B., Bates, Phil, Counihan, T.D., 2001, A simulation study of factors controlling white sturgeon recruitment in the Snake River, in Van Winkle, Webster, Anders, P.J., Secor, D.H., and Dixon, D.A., eds., Biology, management, and protection of North American sturgeon: American Fisheries Society, Symposium 28, August 23-24, 2000, 24 p.

Jager, H.I., Peterson, D.L., Farrae, Daniel, and Bevelhimer, M.S., 2013, A population model to assess influences on the viability of the shortnose sturgeon population in the Ogeechee River, Georgia: Transactions of the American Fisheries Society, v. 142, no. 3, p. 731-746. [Also available at http://dx.doi.org/10.1080/00028487.2013.763853.]

Keenlyne, K.D., Grossman, E.M., and Jenkins, L.G., 1992, Fecundity of the pallid sturgeon: Transactions of the American Fisheries Society, v. 121, no. 1, p. 139-140. [Also available at http://dx.doi.org/10.1577/15488659(1992)121<0139:FOTPS>2.3.CO;2.] 
Kennedy, A.J., Sutton, T.M., and Fisher, B.E., 2006, Reproductive biology of female shovelnose sturgeon in the Upper Wabash River, Indiana: Journal of Applied Ichthyology, v. 22, no. 3, p. 177-182. [Also available at http://dx.doi.org/10.1111/j.1439-0426.2006.00745.x.]

Mayden, R.L., and Kuhajda, B.R., 1997, Threatened fishes of the world-Scaphirhynchus albus (Forbes \& Richardson, 1905) (Acipenseridae), part 3 of Birstein, V.J., Waldman, J.R., and Bemis, W.E., Sturgeon biodiversity and conservation: Developments in Environmental Biology of Fishes, v. 17, p. 420-421. [Also available at http://dx.doi. org/10.1007/0-306-46854-9_31.]

Morris, W.F., and Doak, D.F., 2002, Quantitative conservation biology - Theory and practice of population viability analysis: Sutherland, Mass., Sinauer Associates, Inc. Publishers, $480 \mathrm{p}$.

Nazari, R.M., Sohrabnejad, Mehdi, and Ghomi, M.R., 2009, The effect of maternal size on larval characteristics of Persian sturgeon Acipenser persicus: Aquaculture Research, v. 40, no. 9, p. 1083-1088. [Also available at http://dx.doi. org/10.1111/j.1365-2109.2009.02202.x.]

Pine, W.E., III, Allen, M.S., and Dreitz, V.J., 2001, Population viability of the Gulf of Mexico sturgeon-Inferences from capture-recapture and age-structured models: Transactions of the American Fisheries Society, v. 130, no. 6, p. 11641174. [Also available at http://dx.doi.org/10.1577/15488659(2001)130<1164:PVOTGO>2.0.CO;2.]

Reed, J.M., Mills, L.S., Dunning, J.B., Menges, E.S., McKelvey, K.S., Frye, Robert, Beissinger, S.R., Anstett, Marie-Charlotte, and Miller, Philip, 2002, Emerging issues in population viability analysis: Conservation Biology, v. 16, no. 1, p. 7-19. [Also available at http://dx.doi. org/10.1046/j.1523-1739.2002.99419.x.]

Shuman, D.A., Klumb, R.A., Wilson, R.H., Jaeger, M.E., Haddix, T., Gardner, W.M., Doyle, W.J., Horner, P.T., Ruggles, M., Steffensen, K.D., Stukel, S., and Wanner, G.A., 2011, Pallid sturgeon size structure, condition, and growth in the Missouri River Basin: International Symposium on Sturgeon, 6th, Wuhan, China, October 25-31, 2009 [Proceedings], Journal of Applied Ichthyology, v. 27, no. 2, p. 269-281. [Also available at http://dx.doi. org/10.1111/j.1439-0426.2010.01645.x.]
Steffensen, K.D., Pegg, M.A., and Mestl, G., 2013, Population prediction and viability model for pallid sturgeon (Scaphirhynchus albus, Forbs and Richardson, 1905) in the Lower Missouri River: Journal of Applied Ichthyology, v. 29, no. 5, p. 984-989. [Also available at http://dx.doi. org/10.1111/jai.12277.]

U.S. Fish and Wildlife Service, 2003, Amendment to the 2000 biological opinion on the operation of the Missouri River main stem reservoir system, operation and maintenance of the Missouri River bank stabilization and navigation project, and operation of the Kansas River reservoir system: Minneapolis, Minn., U.S. Army Corps of Engineers, U.S. Fish and Wildlife Service, $308 \mathrm{p}$.

Van Dyke, Fred, 2008, Conservation biology - Foundations, concepts, applications ( $2 \mathrm{~d}$ ed.): Springer Science and Business Media, $478 \mathrm{p}$.

Van Eenennaam, J.P., and Doroshov, S.I., 1998, Effects of age and body size on gonadal development of Atlantic sturgeon: Journal of Fish Biology, v. 53, no. 3, p. 624-637. [Also available at http://dx.doi.org/10.1111/j.1095-8649.1998. tb01006.x.]

Vélez-Espino, L.A., and Koops, M.A., 2009, Recovery potential assessment for lake sturgeon in Canadian designatable units: North American Journal of Fisheries Management, v. 29, no. 4, p. 1065-1090. [Also available at http://dx.doi. org/10.1577/M08-034.1.]

Wildhaber, M.L., Albers, J.L., Green, N.S., and Moran, E.H., 2015, A fully-stochasticized, age-structured population model for population viability analysis of fish-Lower Missouri River endangered pallid sturgeon example: Ecological Modeling. [Also available at http://dx.doi.org/10.1016/j. ecolmodel.2015.07.019.]

Wildhaber, M.L., and Bryan, J.L., 2006, Ultrasonic and endoscopic examination of Lower Missouri and Lower Mississippi pallid sturgeon to determine sex and 2006 broodstock potential: Yankton, S. Dak., U.S. Army Corps of Engineers, Threatened and Endangered Species Section, 12 p.

Wildhaber, M.L., Yang, W.H., and Arab, A., 2014, Population trends, bend use relative to available habitat and withinriver-bend habitat use of eight indicator species of Missouri and Lower Kansas River benthic fishes - 15 years after baseline assessment: River Research and Applications, v. 32, no. 1, p. 36-65. [Also available at http://dx.doi.org/10.1002/ rra.2846.] 
